\title{
Hyperglycemia and xerostomia are key determinants of tooth decay in type 1 diabetic mice
}

\author{
Chih-Ko Yeh ${ }^{1,2}$, Stephen E Harris ${ }^{3}$, Sumathy Mohan ${ }^{4}$, Diane Horn ${ }^{4}$, Roberto Fajardo ${ }^{5}$, Yong-Hee Patricia Chun ${ }^{3}$, \\ James Jorgensen ${ }^{4}$, Mary MacDougall ${ }^{6}$ and Sherry Abboud-Werner ${ }^{2,4}$
}

Insulin-dependent type 1 diabetes mellitus (DM) and oral diseases are closely interrelated. Poor metabolic control in diabetics is associated with a high risk of gingivitis, periodontitis and tooth loss. Salivary flow declines in diabetics and patients suffer from xerostomia. Reduced saliva predisposes to enamel hypomineralization and caries formation; however, the mechanisms that initiate and lead to progression of tooth decay and periodontitis in type 1 DM have not been explored. To address this issue, we analyzed tooth morphology in Akita $-/-$ mice that harbor a point mutation in the Ins2 insulin gene, which leads to progressive hyperglycemia. Mandibles from Akita -/- and wild-type littermates were analyzed by microCT, scanning EM and histology; teeth were examined for amelogenin (Amel) and ameloblastin (Ambn) expression. Mice were injected with pilocarpine to assess saliva production. As hyperglycemia may alter pulp repair, the effect of high glucose levels on the proliferation/differentiation of cultured MD10-F2 pulp cells was also analyzed. Results showed that Akita $-/-$ mice at 6 weeks of age showed chalky white incisors that correlated with marked hyperglycemia and impaired saliva production. MicroCT of Akita $-/$ - teeth revealed excessive enamel wearing and hypomineralization; immunostaining for Amel and Ambn was decreased. A striking feature was invasion of dentinal tubules with Streptococcus mitis and microabcesses that originated in the coronal pulp and progressed to pulp necrosis and periapical periodontitis. High levels of glucose also inhibited MD10-F2 cell proliferation and differentiation. Our findings provide the first evidence that hyperglycemia in combination with reduced saliva in a model of type1 DM leads to decreased enamel mineralization/ matrix proteins and predisposes to excessive wearing and decay. Importantly, hyperglycemia adversely affects enamel matrix proteins and pulp repair. Early detection and treatment of hyperglycemia and hyposalivation may provide a useful strategy for preventing the dental complications of diabetes and promoting oral health in this population.

Laboratory Investigation (2012) 92, 868-882; doi:10.1038/labinvest.2012.60; published online 26 March 2012

KEYWORDS: diabetes; enamel; hyperglycemia; pulpitis; saliva

Diabetes mellitus (DM) type 1, known as insulin-dependent $\mathrm{DM}$, and insulin-independent type $2 \mathrm{DM}$ affects over 20 million individuals in the United States. ${ }^{1}$ These patients have a high incidence of gingivitis, periodontitis, oral candidiasis and xerostomia, and the severity of these diseases correlate with the duration of diabetes and degree of glycemic control. $^{2-4}$ The association of dental caries with diabetes is less clear; however, diabetic patients with reduced salivary flow because of neural defects are at increased risk for enamel hypomineralization and caries formation. ${ }^{5}$ In type 1 diabetes, patients with $\mathrm{HgA}_{1 c}$ levels $>8.0 \%$ exhibited saliva with higher glucose levels, lower $\mathrm{pH}$ and increased lactobacilli and a higher incidence of caries compared with well-controlled diabetics. ${ }^{6-8}$

The homozygous Akita - /- mouse clinically resembles juvenile onset DM type 1 . These mice harbor a mutation of the Cys96Tyr in the murine Ins2 gene that disrupts a disulfide covalent bond between the A7 and B7 chains of proinsulin, leading to insulin deficiency at birth. ${ }^{9}$ Serum glucose levels are elevated by 2 weeks postnatal and progressively increase

\footnotetext{
${ }^{1}$ Department of Comprehensive Dentistry, University of Texas Health Science Center at San Antonio, San Antonio, TX, USA; ${ }^{2}$ Geriatric Research Education and Clinical Center (GRECC) and Pathology, South Texas Veterans Healthcare System, San Antonio, TX, USA; ${ }^{3}$ Department of Periodontics, University of Texas Health Science Center at San Antonio, San Antonio, TX, USA; ${ }^{4}$ Department of Pathology, University of Texas Health Science Center at San Antonio, San Antonio, TX, USA; ${ }^{5}$ Department of Orthopedics, University of Texas Health Science Center at San Antonio, San Antonio, TX, USA and ${ }^{6}$ Institute of Oral Health Research, University of Alabama at Birmingham, Birmingham, AL, USA

Correspondence: Dr S Abboud-Werner, MD, Department of Pathology, Geriatric Research Education and Clinical Center (GRECC), South Texas Veterans Healthcare System, San Antonio, TX 78229, USA.

E-mail: abboudwerner@uthscsa.edu

Received 10 November 2011; revised 26 January 2012; accepted 27 January 2012
} 
with age. This is associated with reduced growth rate and body fat, polyuria, polydipsia, retinopathy, neurologic deficits and, if left untreated, death within 4 months because of extreme hyperglycemia. Chronic hyperglycemia in Akita mice has been reported to predispose to leukocyte defects and increased ligature-induced periodontal bone loss although tooth morphology and salivary gland function have not been examined. ${ }^{10}$

Enamel defects including hypomineralization and increased wearing have been reported in mice with type 2 diabetes $(\mathrm{db} /$ $\mathrm{db}, \mathrm{ob} / \mathrm{ob}) .{ }^{11-13}$ Whitish enamel, hypoplasia and mineralization defects have also been detected in primary teeth of children and in newborns and rodent offspring born to diabetic mothers. ${ }^{14-16}$ Non-obese diabetic (NOD) mice, a model of autoimmune type 1 diabetes and Sjogren's syndrome that shows lymphocytic infiltrates in salivary glands, have been used to examine the effect of diabetes on salivary gland function and periapical tooth infections. ${ }^{17}$ However, the biologic effect of type $1 \mathrm{DM}$ on the tooth phenotype has not been well-defined nor have time course studies been performed to assess the mechanisms involved in the initiation and progression of dental disease in type 1 diabetic rodents. We hypothesized that hyperglycemia and impaired saliva production would contribute to enamel defects in Akita $-/-$ mice. To address these issues, teeth from WT and Akita $-/-$ mice from 2 to 12 weeks of age were examined by X-ray, microCT, scanning EM and histology and salivary gland function was assessed. As hyperglycemia has been reported to inhibit pulp repair, we determined the effect of high glucose levels on the proliferation and differentiation of cultured MD10-F2 dental pulp cells.

Our findings provide the first evidence that hyperglycemia and reduced saliva production in Akita $-/-$ mice by 6 weeks of age leads to hypomineralization, decreased enamel matrix protein expression and excessive enamel wearing compared with WT mice. A striking feature in Akita $-/-$ mice was the migration of oral bacteria through exposed dentinal tubules and initiation of abscesses in the coronal pulp that progressively spread to the dental root and periodontal structures. Cultured pulp cells, treated with high D-glucose, but not L-glucose, showed impaired proliferation and differentiation, suggesting that hyperglycemia mediates its action via a metabolic effect. Importantly, these studies suggest a novel role for hyperglycemia in regulating enamel matrix proteins and indicate that strategies to normalize glucose and saliva levels in tandem may prevent the onset of enamel deterioration/caries and improve oral health in diabetic patients.

\section{MATERIALS AND METHODS \\ Mice}

Heterozygous C57Bl/6-Ins2 ${ }^{\text {Akita }}$ mice, obtained from Jackson Laboratory (Bar Harbor, MA, USA), were bred to generate homozygous Ins2Akita mice (denoted Akita $-/-$ mice). ${ }^{9,18}$ Homozygous male and female Akita $-/-$ mice were used in experiments as both genders have been reported to show comparable blood glucose levels and diabetic phenotype. ${ }^{19}$
Control mice consisted of wild-type $(+/+)$ littermates that were age and sex matched to the Akita $-/$ - group. At 2 to 12 weeks of age, mandibles from Akita $-/$ - and wild-type littermates were excised and teeth were analyzed grossly and by $\mathrm{X}$-ray, microCT, scanning EM and histology. For each time point, at least three mice of each genotype were examined. Blood glucose was measured from the tail vein at killing using a digital glucometer that has a maximal detection limit of $33.3 \mathrm{mM}$ (Accu-Chek Advantage). Animal protocols were approved by the Audie Murphy VA Institutional Animal Care and Use Committee.

\section{Radiographic and MicroCT Analysis}

Hemimandibles from mice were cleaned of soft tissue and radiographs were performed using a MX-20 Faxitron unit equipped with a digital camera (Faxitron X-ray). Analysis of hemimandibles by microCT was performed using a highresolution scanner ( $\mu \mathrm{CT}-40$, Scanco Medical, Switzerland) at Numira Biosciences (Salt Lake, UT, USA). Samples were exposed to polychromatic X-rays on a rotating stage at a step angle of $0.18^{\circ}$ over $360^{\circ}$. Measurements were taken at an operating voltage of $70 \mathrm{kVp}$ and $114 \mu \mathrm{A}$ of current and $6 \mu \mathrm{m}$ isotropic voxel resolution, with an exposure time of $200 \mathrm{~ms}$ and five frames averaged per view. Quantitative 3-D measurements of the first molar crown and root structures were performed using Seg3D software. Briefly, regions of interest were assigned a color and values were calculated for each parameter. Crown measurements included total crown volume that encompassed both enamel and dentin volumes, enamel (yellow), dentin (orange) and pulp (green) volume. Root measurements included total root volume, dentin (pink), root canal (brown) and periodontal volume (blue). Mineral density measurements were also obtained for enamel and dentin in a consistent region of the first molar using the microCT instrument calibrated against known mineral densities.

\section{Scanning Electron Microscopy (SEM)}

Mandibles from Akita - /- and wild-type mice were fixed in $2 \%$ glutaraldehyde in $0.1 \mathrm{M}$. cacodylate buffer. Teeth, after fracture, were ethanol-dehydrated, immersed in three changes of hexamethyldisalizane and air dried. Samples were mounted on aluminum stubs, off-gassed in a vacuum dessicator overnight and sputter-coated with an Au-Pd film as previously described. ${ }^{20}$ Image analysis was performed using an Amray EF 1910 field-emission scanning electron microscope (Billerica, MA, USA).

\section{Histology, Immunohistochemical Stains and RT-PCR}

Mandibles were fixed in $10 \%$ buffered formalin, decalcified in $12 \%$ EDTA and embedded in paraffin. In all, $5-\mu \mathrm{m}$ thick sections were stained with $\mathrm{H} \& \mathrm{E}$ to evaluate morphology, Brown \& Hopp's stain to detect gram-positive/negative bacterial organisms and tartrate resistant acid phosphatase (TRAP) to identify osteoclasts as previously described. ${ }^{21}$ Immunohistochemical staining was performed to assess 
amelogenin (Amel) and ameloblastin (Ambn) expression in ameloblasts using a rabbit polyclonal anti-human Amel (FL191) and goat polyclonal anti-human Ambn (C-17); 1:100, Santa Cruz. Following incubation with each primary antibody, sections were incubated with a standard HRP-polymer detection kit (Biocare Medical) and 3,3'-diaminobenzidine substrate was used to visualize immunoreaction sites. To examine Amel and Ambn mRNA expression, total RNA was isolated from WT and Akita -/- incisors with TRI Reagent (Sigma-Aldrich) and subjected to RT-PCR using specific primer sets as previously described. ${ }^{22}$ PCR products were analyzed in $1 \%$ agarose gels and the density of each band was measured using ImageJ software (NIH, Bethesda, MD, USA). The densities of marker mRNA bands were normalized relative to those of $18 \mathrm{~S}$ mRNA bands. Data are expressed as relative mRNA expression where the ratio of the Amel and Ambn band density in control WT samples to the corresponding $18 \mathrm{~S}$ signal was arbitrarily set at 1 .

Parotid glands were excised from a subset of mice injected with pilocarpine. Parotid glands were chosen for analysis since, of all salivary glands, rodent parotid glands are structurally and functionally similar to the human parotid. ${ }^{23}$ Samples were processed for H\&E to examine morphology and Periodic Acid Schiff (PAS) with diastase to assess glycogen containing acinar structures. To quantify the number of ducts within the parotid gland, ducts were counted within the entire tissue area using a Bioquant image analysis system and data is expressed as ducts $/ \mathrm{mm}^{2}$ of tissue. Submandibular glands were also removed from the same mice and analyzed for morphology on routine H\&E stained sections.

\section{Transmission Electron Microscopy}

To examine the ultrastructure of secretory granules in parotid gland acini, tissue was fixed and embedded in epoxy resin. Ultrathin sections were stained with uranyl acetate and lead citrate and examined using a Joel 1230 electron microscope (Loel, Tokyo, Japan).

\section{Bacterial Culture Analysis}

Carious first molars from Akita $-/$ - mice were placed in sterile PBS and, within $30 \mathrm{~min}$ after harvest, the pulp was removed, vortexed and suspensions were used to inoculate trypticase soy agar with $5 \%$ sheep blood, Columbia CNA agar with 5\% sheep blood, chocolate agar and Candida ChromAgar plates (BD Microbiology, Sparks, MD, USA). Cultures were incubated at $35^{\circ} \mathrm{C}$ for $72 \mathrm{~h}$ in an atmosphere of $5 \% \mathrm{CO}_{2}$ and organisms were identified according to standard criteria.

\section{Analysis of Saliva Production}

A subset of wild-type and Akita $-/-$ mice were tested for saliva production. Mice were injected with pilocarpine ( $2.5 \mu \mathrm{g} / \mathrm{g}$ BW intraperitoneally), a muscarinic receptor agonist, to stimulate saliva production as previously described. ${ }^{24}$ Each mouse was immobilized in a conical tube and saliva was collected through a plastic tube attached to a vacuum pump for $5 \mathrm{~min}$ beginning at the time of appearance of saliva in the oral cavity. Saliva was placed into chilled $1.5 \mathrm{ml}$ microcentrifuge tubes and volume was calculated based on weight change of the preweighed tubes using an analytical balance.

\section{Pulp Cell Proliferation Assay}

MD10-F2 cells have a dental pulp-like phenotype and were cultured as previously described. ${ }^{25}$ These cells were originally isolated from dental papilla mesenchymal cells of the first mandibular molars of Swiss Webster mice at embryonic day 18 and immortalized using an SV-40 large T antigen vector. ${ }^{25}$ Cells were seeded into 12 -well dishes at $8 \times 10^{3}$ cells per well in $\alpha$-MEM containing $10 \%$ fetal calf serum (FCS). $\alpha$-MEM contains $5.5 \mathrm{mM}$ D-glucose (that is normally present in basal medium) and used as a normal glucose control. After $24 \mathrm{~h}$, cultures were placed in $\alpha$-MEM with $2 \%$ FCS and incubated with additional $10 \mathrm{mM}$ or $25 \mathrm{mM}$ of $\mathrm{D}(+)$ glucose (high D-Glucose). As an osmotic control, cells were incubated with $10 \mathrm{mM}$ or $25 \mathrm{mM}$ of $\mathrm{L}(-)$ glucose (high L-Glucose). Addition of glucose ( 10 or $25 \mathrm{mM}$ ) to the $\alpha$-MEM led to a final concentration of 15.5 or $30.5 \mathrm{mM}$, respectively). Medium was changed after 2 days and cell counts were performed using a hemocytometer on day 4 .

\section{Pulp Cell Differentiation Assay}

The effect of glucose on MD10-F2 cell differentiation was examined using a standard differentiation assay. ${ }^{25}$ Confluent cells in 24-well dishes were incubated in the presence or absence of increasing doses of glucose for 12 days throughout differentiation. Cultures were divided into four treatment groups: untreated ( $\alpha$-MEM supplemented with $5 \%$ FCS), differentiation medium ( $\alpha$-MEM with $5 \%$ FCS, $50 \mu \mathrm{g} / \mathrm{ml}$ ascorbic acid and $10 \mathrm{mM}$ sodium $\beta$-glycerolphosphate), differentiation medium with additional $10 \mathrm{mM}$ or $25 \mathrm{mM}$ D-glucose (high D-glucose) or differentiation medium with $10 \mathrm{mM}$ or $25 \mathrm{mM}$ L-glucose (osmotic control). Medium was changed every 2 days and, at harvest, cultures were stained with von Kossa that stains mineralized nodules black.

\section{Statistical Analysis}

The means and standard errors (s.e.) of all numeric data were calculated. Data were analyzed statistically using the unpaired Student's $t$-test. Differences were considered statistically significant for comparisons of data sets yielding $P \leq 0.05$.

\section{RESULTS}

Previous studies have shown that Akita - /- mice have normal serum glucose at birth and levels increase with age. We, therefore, monitored serum glucose in WT and Akita - Imice from 10 days to 9 weeks postnatal. Compared with WT mice, glucose values in Akita -/- mice were slightly increased at 10 days, higher at 4 weeks and dramatically elevated from 6 to 9 weeks of age (Table 1). No gender differences in blood glucose levels were observed in Akita - /mice (6-week females, 28.1 to $>33.3 \mathrm{mM}$; 6-week males, 21.4 
Table 1 Serum glucose and body weight

\begin{tabular}{|c|c|c|c|c|}
\hline \multirow[t]{2}{*}{ Age } & \multicolumn{2}{|c|}{ Glucose (mM) } & \multicolumn{2}{|c|}{ Body weight (g) } \\
\hline & WT & Akita -/- & WT & Akita -/- \\
\hline $10 \mathrm{~d}$ & $5.90 \pm 0.18$ & $8.39 \pm 0.10^{\star * *}$ & $4.62 \pm 0.29$ & $4.36 \pm 0.17$ \\
\hline 4 wk & $10.45 \pm 0.79$ & $25.03 \pm 6.09^{* *}$ & $15.45 \pm 1.02$ & $7.88 \pm 0.45^{* * *}$ \\
\hline 6 wk & $9.59 \pm 0.47$ & $31.09 \pm 0.80^{* * *, a}$ & $17.69 \pm 0.55$ & $7.45 \pm 0.18^{* * *}$ \\
\hline 9 wk & $9.55 \pm 2.15$ & $>33.3^{* *}$ & $24.45 \pm 0.35$ & $10.20 \pm 0.70^{* *}$ \\
\hline
\end{tabular}

Abbreviations: d, day; wk, week.

${ }^{\mathrm{a}}$ Glucose values were averaged and included six mice with levels $>33.3 \mathrm{mM}$. $n=5-15$ mice per group; ${ }^{* *} P<0.001,{ }^{* *} P<0.01$ Akita $-/-v s$ WT mice.

to $>33.3 \mathrm{mM}$ ). Hyperglycemia in Akita $-/-$ mice was also associated with reduced growth rate and body weight (Table 1). To determine whether Akita $-/-$ mice develop an abnormal dental phenotype, gross tooth morphology and radiographic images of mandibles excised from WT and Akita $-/-$ mice at 2 to 12 weeks of age were examined. The onset of tooth eruption in Akita $-/$ - was normal and, at 2 and 3 weeks, the tooth shape, size and color were indistinguishable from WT (Figure 1a). By 4 to 5 weeks, incisor shape in Akita $-/-$ mice was similar to WT although the occlusal two-thirds of the mandibular and maxillary incisors appeared more chalky white in color (Figure 1b). On lingual views of the mandibular molars (M1-M3), a significant difference in molar morphology between Akita $-/-$ and WT mice was not detected at 4 weeks. Radiographs also showed well-formed crown, root and periodontal structures in Akita $-/-$ mice similar to WT mice. In contrast, at 6 weeks, Akita -/- incisors showed a diffuse chalky white appearance with wearing along the tips (Figure 1c). All three molars showed altered crown morphology with rounded cusp tips and increased wearing along all biting surfaces. By X-ray, Akita -/- mice showed incisors with blunted tips and molars with abraded cusps and decreased enamel radiodensity. At 12 weeks of age, WT mice showed well-preserved crown and root structures (Figure 1d, left panel), whereas in Akita $-/-$ mice, there was dramatic wearing of molar crowns and exposed pulp chambers (Figure 1d, right panel). X-rays of Akita - /- mandibles showed flattened molar crowns and radiolucent alveolar around roots and in between teeth because of bone loss.

As Akita $-/-$ incisors began to show a chalky white appearance at 4 weeks, tooth morphology was examined in more detail using microCT. Figure 2a shows that Akita -/incisors had smooth surfaces and slightly more rounded tips, prone to wearing compared with WT incisors. The molars in Akita - /- mice showed normal crown development, bifurcation of roots and alveolar bone. However, Akita -/molars showed increased wearing of enamel along the cusp tips (Figure 2b). This correlated with the morphology of whole molars analyzed by SEM. WT molars showed wellformed cusp tips, whereas Akita - / - molars showed abraded enamel along buccal and occlusal biting surfaces (Figure 2c). To evaluate enamel structure, incisors were fractured proximal to the tip. Akita $-/-$ incisors showed well-organized enamel of normal thickness and a normal pattern of decussating enamel rods (Figure 2d, upper panel) with crystallites within each rod being parallel to one another (Figure 2d, lower panel). These findings suggest that enamel formation occurs normally during early tooth development in Akita $-/-$ mice when they are not substantially hyperglycemic.

Molars from 6- to 12-week-old mice were further examined by microCT. 3-D images of Akita - /- molars showed progressively increased wearing of crowns from 4 to 6 weeks of age (Figure 3a). 2-D gray scale sagittal slices (depict enamel as white) of the Akita $-/-$ molars confirmed a reduction in enamel notably at the cusp tips, whereas root and periodontal structures were normal (Figure $3 \mathrm{~b}$ ). To quantify molar structures, 3-D volumetric measurements of color segmented crown and root structures was performed (Figure 3c). Akita $-/-$ molars in 6-week-old mice showed a significant reduction in total crown volume because of decreased enamel volume, whereas root and periodontal volumes were similar to WT (Figure 3d, bar graph). Interestingly, Akita $-/-$ molars showed an abnormal dentin contour along the pulp interface and increased pulp volume, likely due to microabscess formation in the coronal pulp (histology shown below). By 12 weeks of age, the crowns of all three molars in Akita $-/-$ mice were flattened (Figures $3 e$ and $\mathrm{f}$ ). In Akita $-/$ - first molars, the crown volume was markedly reduced compared with that in WT mice because of loss of both enamel and dentin and the root volume was decreased because of decreased dentin (data not shown). The pulp chambers in Akita $-/-$ molars were exposed and increased (Figure 3f, arrows) and the periodontal volume was increased because of bone loss around roots (Figure 3f, asterisks).

Teeth from 6-week-old mice were further assessed. Split microCT images of enamel and dentin in the crown of isolated first molars at 6 weeks demonstrates the flattened cusp tips and intact dentin enamel junction in Akita $-/-$ mice (Figures $4 \mathrm{a}$ and b). Color maps shown in Figures $4 \mathrm{c}$ and $\mathrm{d}$ based on gray scale images of molars where blue represents enamel and green represents dentin confirmed reduced enamel volume in Akita $-/-$ molars and increased enamelfree areas with exposed dentin. Aerial views of the crown surface demonstrated that the pattern of enamel wearing in Akita $-1-$ molars resembled that in WT molars. We next determined if the enamel volume in incisors of Akita - /mice was also altered. For these studies, we utilized a microCT imaging system that animates a perpendicular cutting plane that moves along the 3-D incisor and calculated the average cross-sectional volume of enamel from root to incisor tip (Figure 4e). Results confirmed that Akita -/incisors, similar to molars, have reduced enamel volume (Figure 4e, bar graph). Importantly, Akita - /- teeth also showed a modest reduction in the mineral density of both enamel and dentin (Figure 4f). 


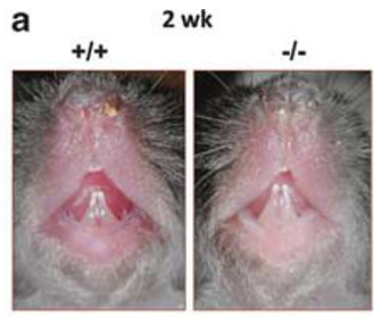

b
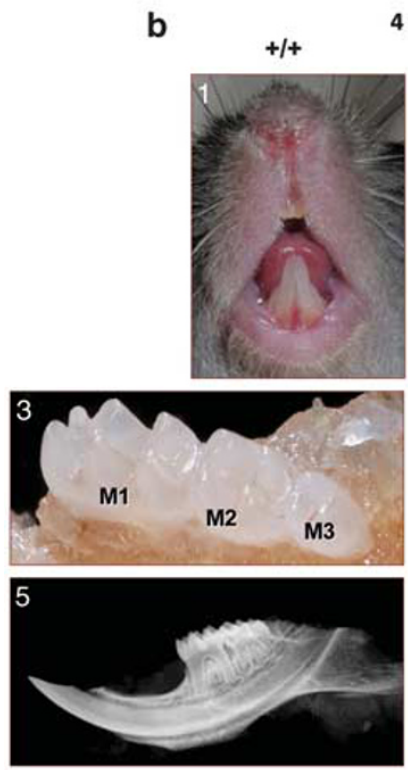

wk
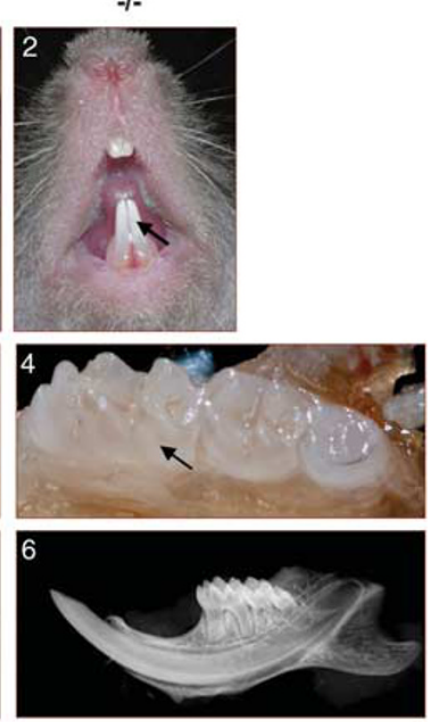

$12 w k+1+$
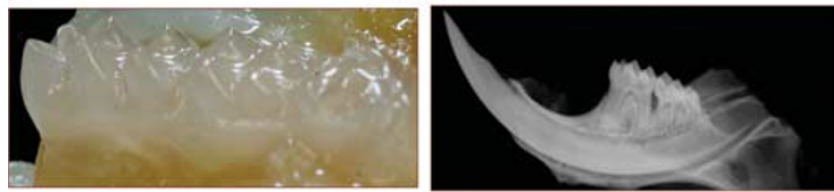

C

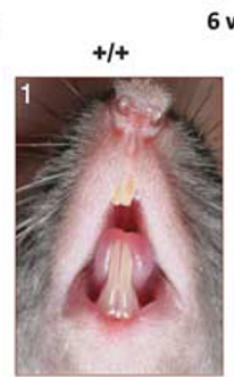

6 wk
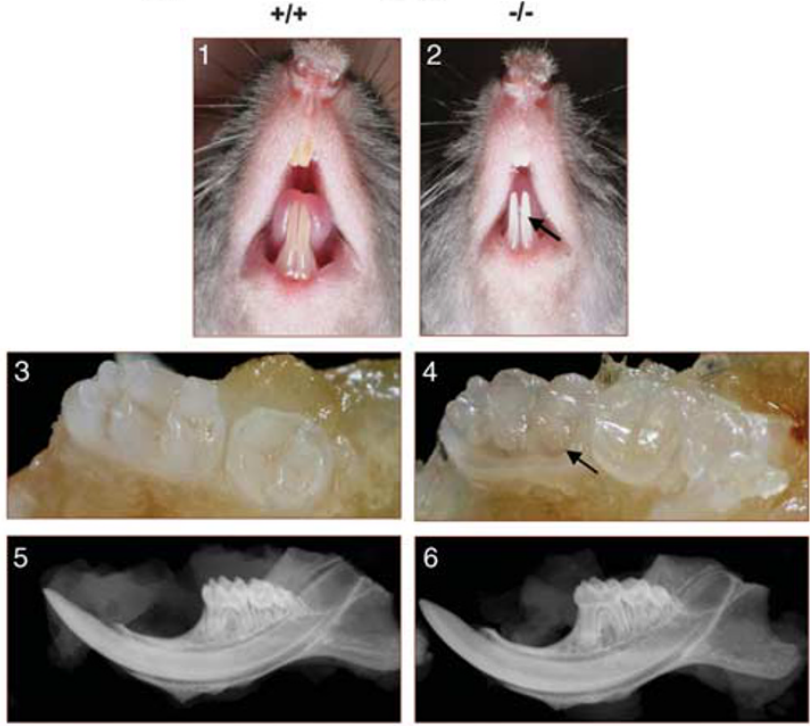

12 wk -l-
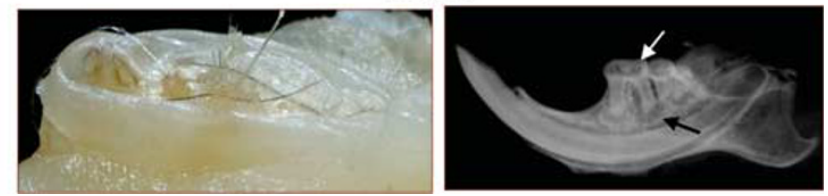

Figure 1 Gross morphology and radiographic images of WT $(+/+)$ and Akita $-/-$ mice. (a) Incisor morphology at 2 weeks of age. Tooth shape, size and color in Akita -/- resembled WT. (b1-6) Four weeks of age and (c1-6) 6 weeks of age: incisor morphology (upper panel) and lingual views of mandibular molars (M1-M3) following removal of soft tissues (middle panel) and radiographs of mandibles (lower panel). At 4 weeks, the distal region of Akita -/incisors appears chalky white; molars and radiographs appear normal. At 6 weeks, Akita -/- incisors appear diffusely white; incisors and molars show increased wearing and on X-ray, molars show decreased enamel radiodensity. (d) Lingual views of mandibular molars and radiographs of mandibles in WT (left panel) and Akita -/- mice (right panel) at 12 weeks of age. Akita -/- molars show severe wearing of cusps and exposed pulp chambers containing hair shaft debris; X-ray shows flattened crowns, exposed pulp chambers, periapical and periodontal radiolucency associated with bone loss. Representative images are shown ( $n=3-8$ mice for each genotype per age group).

As hypomineralization and enamel attrition in 6-week-old Akita - / - molars may predispose to bacterial invasion and caries, ${ }^{26,27}$ histologic sections were examined. Pulp infection in Akita $-/-$ molars began in the pulp horns as microabscesses containing neutrophils, whereas the root pulp and periodontal structures were preserved. Abscesses were not identified in WT molars (Figures 5a and b). Gram stains of Akita -/- molars at 6 weeks of age showed gram-positive cocci along dentin surfaces, invading dentinal tubules and within pulp microabscesses (Figure 5c). By 9 weeks, numerous organisms were identified in dentinal tubules and throughout the coronal pulp chamber and foci of reparative dentin were observed (Figure 5d). Inflammation also extended into the root pulp that showed acute pulpitis. Cultures of pulp tissue from Akita - /- molars showed heavy growth of Streptococcus mitis.

Analysis of Akita -/- teeth at 12 weeks showed destruction of dentin and exposed pulp chambers filled with necrotic/hair shaft debris and bacteria (Figure 6a). On gram stain (Figure 6b), the pulp chamber contained both gram-positive cocci and gram-negative coccobacilli that were identified as Streptococcus mitus and Pasteurella pneumotropica, respectively, bacteria common in oral flora of humans and rodents. ${ }^{28,29}$ There was severe periodontal 

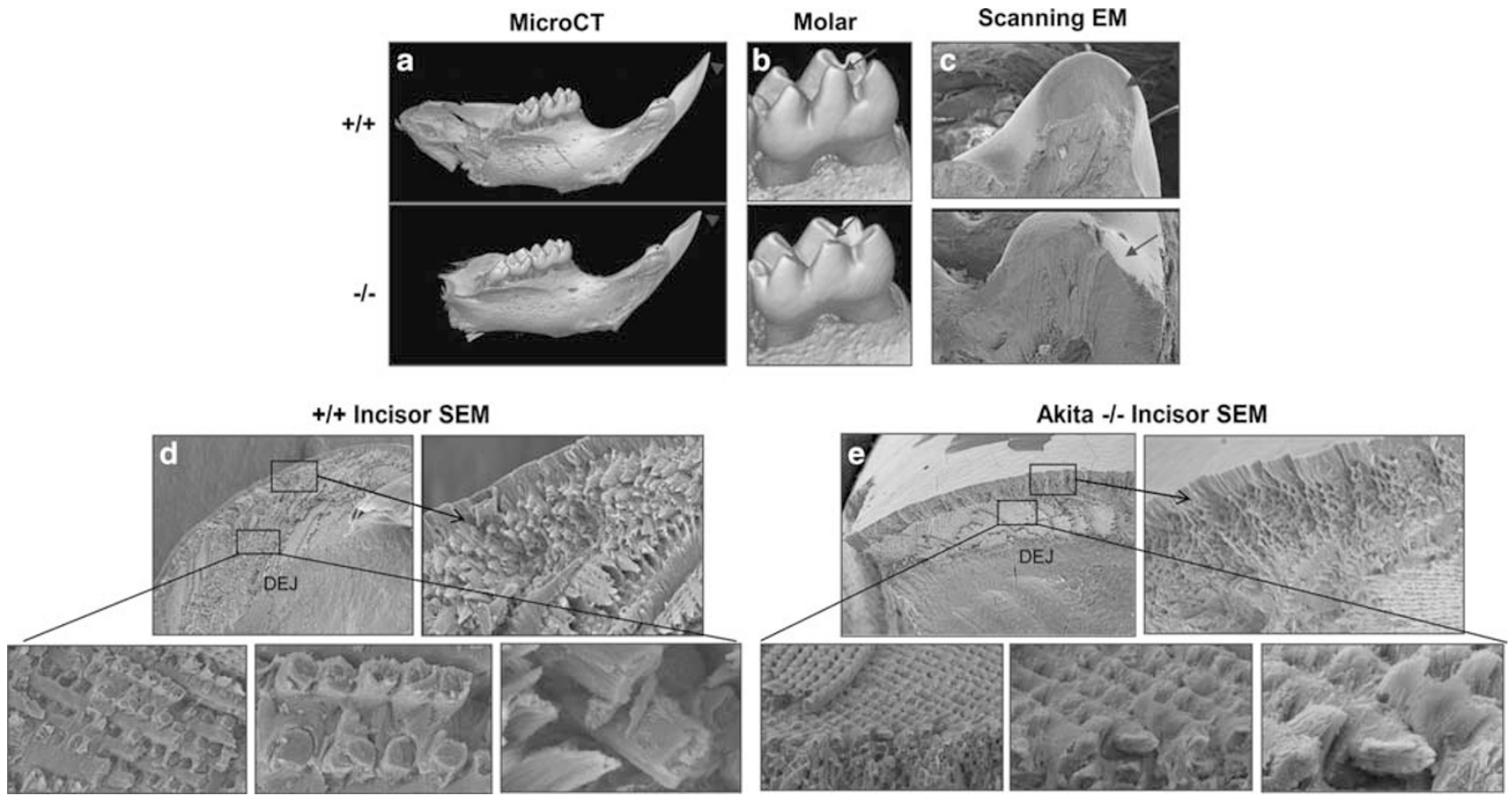

Figure 2 microCT of mandible with first molar and scanning EM of first molar in WT $(+/+)$ and Akita $-/-$ mice at 4 weeks of age. (a, b) 3-D microCT reconstruction of mandible (left) and high-power images of first mandibular molar (right). Akita -/- incisors showed rounded tips, prone to wearing (arrowheads) and, at high power, molars show increased wearing of enamel along cusp tips compared with WT (arrows). (c) Scanning EM of whole molar preparations. WT molars show well-formed cusp tips, whereas Akita $-/-$ molars show abraded enamel along biting surfaces (arrow). (d) Scanning EM of enamel structure of fractured WT and (e) Akita - /- incisors. Akita -/- incisors show enamel of normal thickness with an outer aprismatic layer (upper box) and inner layer (lower box) that shows a normal pattern of decussating enamel rods (lower panel). Representative images are shown ( $n=3$ mice for each genotype).

disease characterized by periapical abscesses; inflammation extended through the apical foramen into the periradicular tissue, causing destruction of roots and alveolar bone (Figure 6c). TRAP stains confirmed extensive osteoclast-mediated bone loss around the roots (Figure 6d). Mucosal surfaces in Akita $-/-$, similar to WT mice, showed few inflammatory cells before 12 weeks, whereas at 12 weeks, Akita -/- mice showed severe gingivitis (Figure 6a) that likely occurred as a result of severe apical periodontitis.

The presence of chalky white teeth in Akita -/- mice suggested that hyperglycemia may alter expression of enamel matrix proteins. Immunostains were therefore performed for Amel and Ambn. At 3 and 10 days of age, before the onset of severe hyperglycemia, Akita - I- molars showed normal Amel and Ambn expression (Figures $7 \mathrm{a}$ and $\mathrm{b}$ ). X-rays of mandibles from 10-day-old Akita $-/$ - mice showed normal molars and incisors and histology also showed enamel and dentin of normal thickness (Figures $7 \mathrm{c}$ and d). However, by 6 weeks of age, immunostains of Akita $-/$ - incisors showed decreased Amel and Ambn expression in secretory through maturation stage ameloblasts (Figures $7 \mathrm{e}$ and $\mathrm{f}$ ). This correlated with a significant reduction of Amel and Ambn mRNA levels in Akita -/- incisors compared with WT incisors (Figure 7, bar graphs).

Saliva provides a critical oral environment to protect teeth from demineralization and bacterial infection. To determine if hypomineralization and caries in Akita $-/-$ mice were associated with decreased saliva, mice were examined for saliva production. Pilocarpine, a muscarinic receptor agonist, was administered to WT and Akita $-/-$ mice to stimulate saliva production. ${ }^{24}$ The average volume of whole saliva collected in WT controls was $170 \mu \mathrm{l}$ per $5 \mathrm{~min}$, whereas little or no saliva was collected from Akita $-/-$ mice (Figure 8a). Both male and female Akita -/- mice showed markedly impaired saliva production (males, 0 to $3 \mu \mathrm{l}$; females, 0 to $2 \mu \mathrm{l}$ ). These findings suggest a link between poor glycemic control and loss of salivary gland function in Akita $-/-$ mice regardless of gender. Parotid and submandibular glands were harvested from the same mice and examined for morphology. Akita $-/-$ parotid glands, as well as submandibular glands (data not shown), showed normal architecture and duct structures; no inflammation or sialitis was identified. The number of ducts per $\mathrm{mm}^{2}$ of parotid tissue in Akita $-1-$ mice was also similar to that in WT mice (Figure 8b, bar graph). However, on PAS stain, parotid acinar cells in Akita $-/-$ mice contained increased PAS-positive secretory granules compared with WT cells (Figure 8c). Increased secretory granules in Akita -/- acini were also identified on EM, suggesting impaired secretion of granules in response to pilocarpine (Figure 8d). In WT acini, secretory granules were decreased in pilocarpine-injected compared with untreated mice, indicating appropriate granule secretion along with 


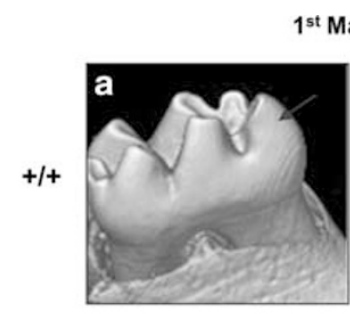

$1^{\text {st }}$ Mandibular Molar 6 weeks
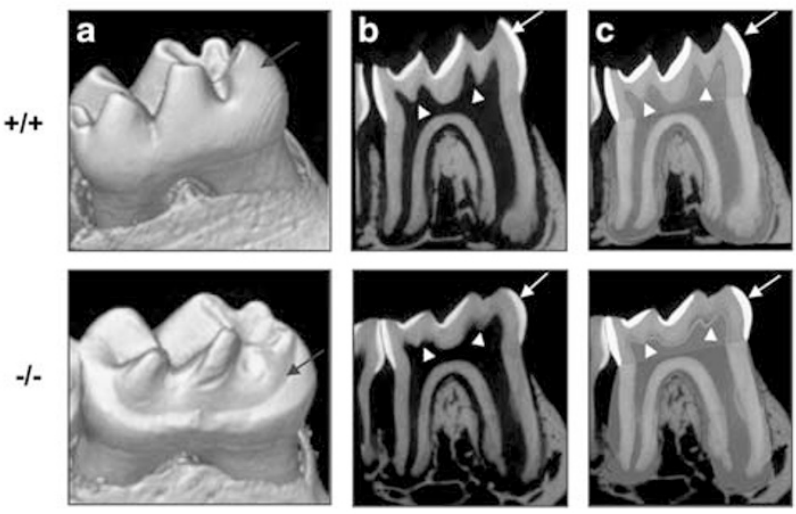

$+/+$ Molar 12 weeks
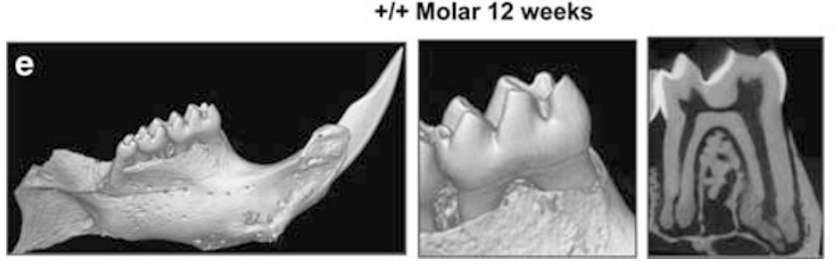

d

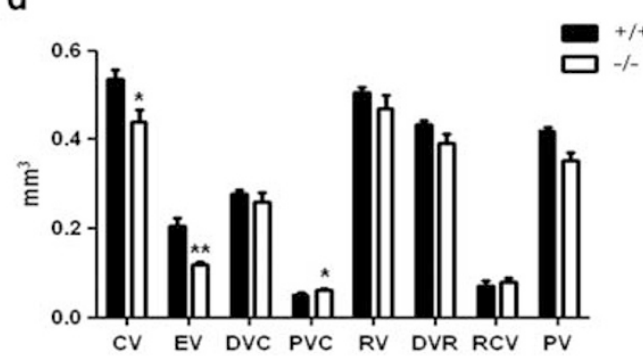

$\mathrm{CV}=$ Total crown volume $\mathrm{EV}=$ Enamel volume crown $\mathrm{DVC}=$ Dentin volume crown $\mathrm{PVC}=$ Pulp volume crown
RV=Total root volume DVR= Dentin volume root $\mathrm{RCV}=$ Root Canal Volume $\mathrm{PV}=$ Periodontal volume

Figure 3 microCT and 3-D volumetric measurements of first mandibular molars in WT $(+/+)$ and Akita $-/-$ mice at 6 and 12 weeks of age. (a-c) Six weeks: 3-D microCT image of first molar (left panel) and corresponding 2-D gray scale (middle panel) and 2-D color segmented (right panel) sagittal slices of the same molar. Akita -/- molars show excessive wearing of crowns compared with WT and decreased enamel along cusp tips (arrows). Abnormal dentin contour along pulp interface is likely due to microabscess formation (arrowheads). (d) Quantitative volumetric measurements of crown and root structures in 6-week molars. Total crown volume is decreased in Akita $-/-$ molars because of decreased enamel volume. Mean \pm s.e. ( $n=3-4$ mice for each genotype) ${ }^{* *} P<0.01,{ }^{*} P<0.05$ WT vs Akita $-/-$ mice. (e, f) Twelve weeks: 3-D microCT of mandible (left panel), first molar (middle panel) and corresponding 2-D gray scale sagittal slice of the same molar. Akita $-/-$ mice show dramatic wearing of molar crowns and exposure of pulp chambers. In Akita - /- molar, total crown volume is decreased because of loss of enamel and dentin (arrows); root volume is decreased because of less dentin (arrowhead) and periodontal volume is increased because of bone loss around roots (asterisks).

fluid secretion (data not shown). In addition, the ultrastructure of secretory granules in Akita $-1-$ acini differed from those in WT, with most granules having a low electron density and appearing light gray surrounded by halos compared with darker granules with electron dense cores in WT cells (Figure 8e). No significant differences in the number of lysosomes or lipid droplets were identified in Akita $-/-$ and WT acini. These findings indicate that saliva production is severely impaired in Akita mice by 6 weeks of age, likely due to a neurologic defect. Taken together, results suggest that reduced saliva contributed to enamel/dentin hypomineralization and, the latter in combination with decreased Amel/ Ambl expression led to chalky white teeth, enamel wearing and acute pulpitis. Moreover, the granule ultrastructure in Akita $-/-$ acini suggests that the salivary gland protein profile differs from that in WT mice.

As Akita - /- mice showed progressive acute pulpitis and high glucose levels have been reported to inhibit cellular repair, ${ }^{3}$ we determined the effect of high glucose on MD10-F2 pulp cells in vitro. Cells were tested for proliferation and differentiation using standard assays in the presence and absence of high D-glucose (15 and $30 \mathrm{mM}$ ). Control cells were incubated with normal D-glucose $(5 \mathrm{mM})$ or with
L-glucose ( 15 or $30 \mathrm{mM})$ as osmotic controls. Figure 9a shows that high D-glucose $(30 \mathrm{mM})$ inhibited pulp cell proliferation $\sim 33 \%$ compared with $5 \mathrm{mM}$ D-glucose and L-glucose-treated controls. In differentiation assays, cultures incubated in differentiation medium containing either $5 \mathrm{mM}$ D-glucose or L-glucose at 15 or $30 \mathrm{mM}$ for 2 weeks showed mineralized nodules (black color) on von Kossa stain (Figure 9b). Nodules were not identified in control cultures without differentiation medium. Compared with L-glucose controls, D-glucose dramatically inhibited mineralized nodule formation. Thus, D-glucose, via a metabolic effect, inhibits pulp cell proliferation and differentiation.

\section{DISCUSSION}

Our results provide the first evidence that hyperglycemia and reduced salivary function in a model of type $1 \mathrm{DM}$ leads to hypomineralization, excessive enamel wearing, acute pulpitis and impaired pulp cell function. Time course studies suggest a sequence of events leading to the formation of caries in Akita $-/-$ mice (summarized in Figure 10). First, from birth to 2 weeks of age, Akita $-/-$ mice show a slow rise in serum glucose, normal tooth morphology and enamel matrix protein expression. From 2 to 6 weeks, progressive hyperglycemia 


\section{Split microCT Images}

$+/+6$ weeks

a
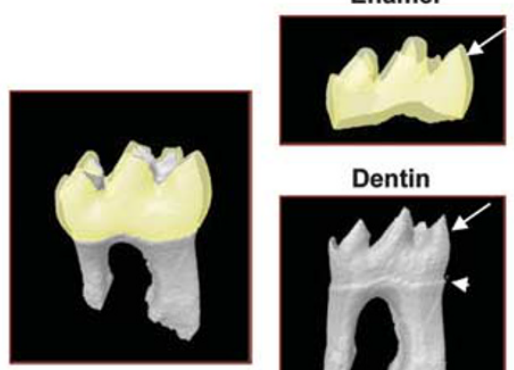

Dentin

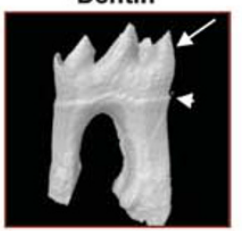

Akita $-/-6$ weeks

b
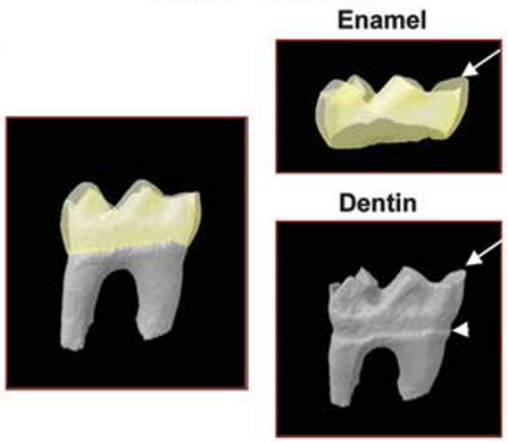

Color Map of Enamel and Dentin

C

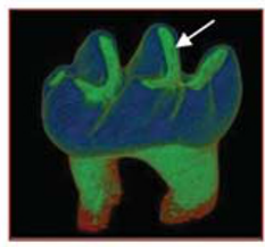

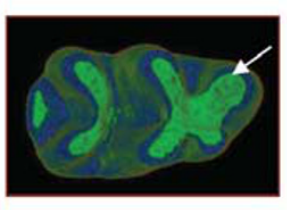

d
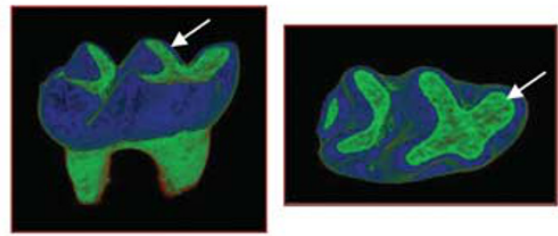

f

e

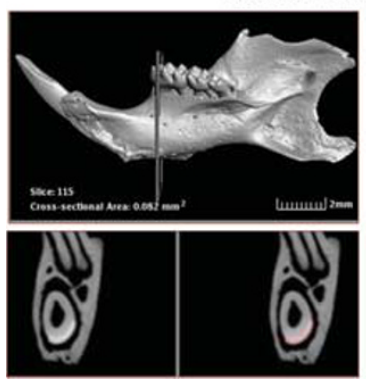

Incisor Enamel C-S Area

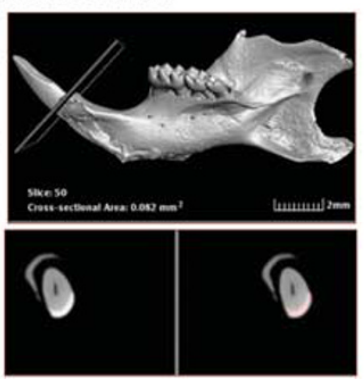

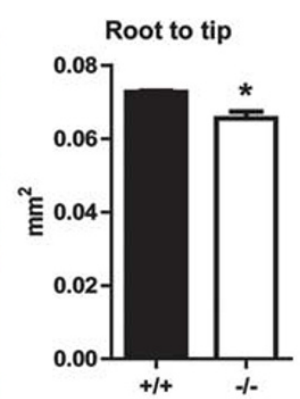

Mineral Density Analysis

Enamel

Dentin

Figure 4 Split microCT images and color maps of first mandibular molars in WT $(+/+)$ and Akita $-/-$ mice at 6 weeks of age. (a, b) Split microCT images of enamel (yellow) and dentin (gray) in the crown. Akita -/- molars show flattened cusps and underlying dentin (arrows); the dentin cementum junction is intact (arrowheads). (c, d) Color maps depicting enamel as blue and dentin as green. Akita - /- molars show reduced enamel volume and increased enamel free areas with exposed dentin (arrows). The pattern of enamel wearing in Akita -/- mice was similar to that in WT. (e) Analysis of enamel volume in 6-week incisors using an animated microCT system. A perpendicular cutting plane that moves along the 3-D incisor from root to incisor tip was used to measure the enamel cross-sectional (C-S) area. A representative WT mandible is shown with the perpendicular cutting plane at two different sites (left and right upper panels). The lower left panels show the perpendicular cross-sectional slice in gray scale; the lower right panels show the enamel overlayed with a pink color. The average cross-sectional area (volume) of enamel along the entire incisor was calculated (shown in bar graph). Mean \pm s.e. ( $n=3-4$ mice for each genotype) ${ }^{\star} P<0.05$ WT vs Akita $-/-$ mice. (f) Analysis of mineral density. Akita $-/-$ teeth show a modest reduction in enamel and dentin mineral density. Mean \pm s.e. ( $n=3-4$ mice for each genotype) ${ }^{*} p<0.01,{ }^{*} p<0.05$ WT vs Akita $-/-$ mice.

occurs. Incisors appear chalky white and teeth show early wearing at 4 weeks; however, enamel structure by SEM is normal, suggesting that enamel alterations are acquired. By 6 weeks, saliva production dramatically declines in Akita -/mice and leads to decreased enamel/dentin remineralization capacity and this, in combination with reduced Amel/Ambn expression, likely contribute to the chalky white phenotype in incisors. These defects are associated with excessive enamel wearing that predisposes to invasion of exposed dentinal tubules by oral bacteria that localize initially in the coronal pulp. With persistent infection, acute pulpitis spreads to the root, leads to pulp necrosis, periapical abscesses and severe periodontitis at 12 weeks. Inhibition of pulp cell proliferation/ differentiation by hyperglycemia may further exacerbate pulp necrosis and periodontal disease.

Diabetic patients and rodents are predisposed to gingivitis and periodontitis; however, with regard to dental caries, some studies, but not others, have reported an increased incidence of dental caries in diabetes. ${ }^{7,30,31}$ In rodents, administration of streptozotocin is the conventional model for type 1 diabetes; however, streptozotocin causes toxic effects in dental cells. $^{32}$ A more appropriate model of type 1 diabetes is the Akita $-/$ - mouse that resembles type 1 diabetes in humans. To our knowledge, previous studies have not examined 

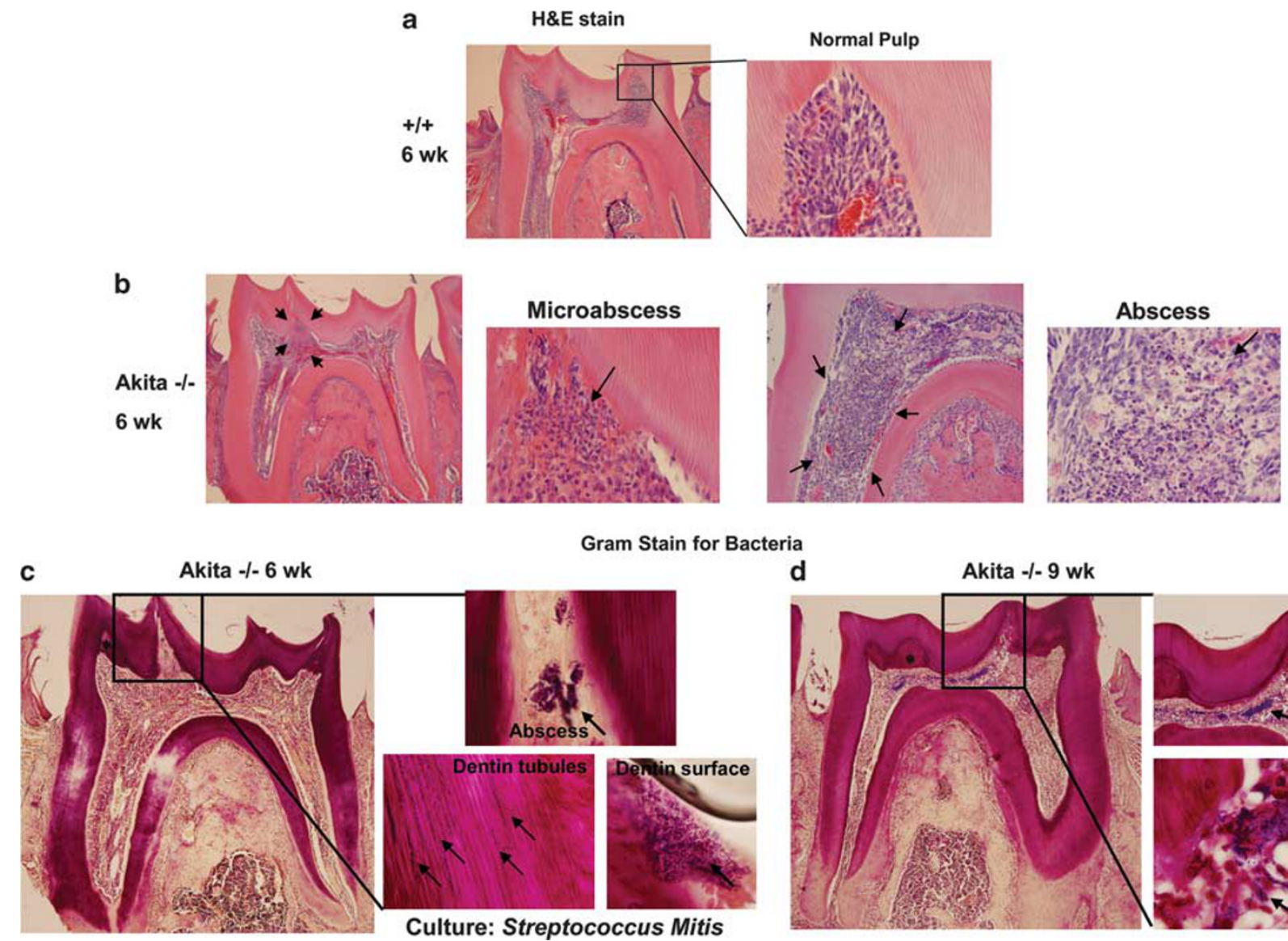

Gram Stain for Bacteria
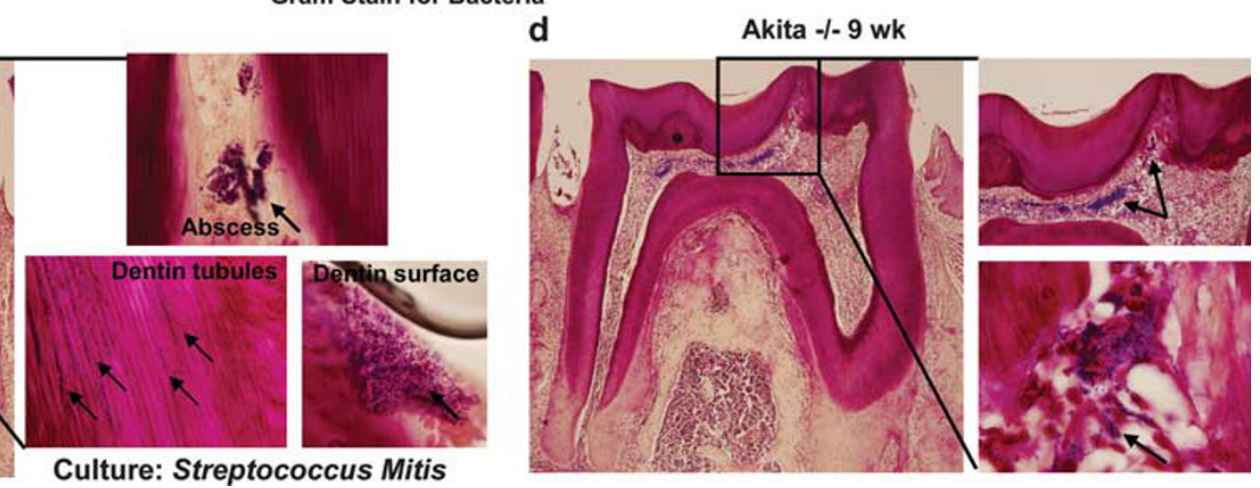

Figure 5 Morphology and gram stain of first mandibular molars in WT $(+/+)$ and Akita $-/-$ mice at 6 and 9 weeks of age. (a, b) H\&E stained sections of molars. WT molars show normal dentin and pulp. Akita -/- molars show microabscesses beginning in the pulp horns (b, left panel, arrows) that enlarged (b, right panel, arrows). (c) Gram stain of Akita -/- molar at 6 weeks. Gram-positive cocci were identified within microabscesses, dentinal tubules and along dentin surfaces (arrows). Small focus of reparative dentin is present (asterisks). (d) Gram stain of Akita $-/-$ molar at 9 weeks. Numerous gram-positive cocci are present throughout the pulp chamber and dentinal tubules (arrows). An occasional focus of reparative dentin is identified (asterisks). Acute pulpitis extended into the root pulp. Cultures of pulp tissue showed heavy growth of $S$. mitis ( $n=3$ mice for each genotype).

Original magnification: a: $\times 4, \times 40 ;$ b: $\times 4, \times 40, \times 20, \times 40 ; \mathbf{c}: \times 4, \times 100 ; \mathbf{d}: \times 4, \times 20, \times 100$.

Akita - / mice for tooth defects. We took advantage of the homozygous Akita $-/-$ mutants that show a rapid progression of hyperglycemia to elucidate the natural course of dental disease in type 1 diabetes. We examined multiple parameters including onset/duration of hyperglycemia, enamel structure, pulp morphology and salivary gland function. Our findings indicate that the onset of hyperglycemia in 4-week-old Akita $-/$ - mice correlated with early enamel wearing as shown by microCT. To quantitate tooth structures, we developed a 3-D color segmentation and color mapping microCT technique, not previously used to examine diabetic rodent teeth, and showed that prolonged hyperglycemia in Akita $-/-$ mice from 4 to 6 weeks was associated with increased enamel wearing of molars and incisors.

The importance of saliva production in maintaining enamel integrity was evident in 6-week Akita $-/-$ mice. Saliva, primarily produced by the acinar cells of salivary glands, contains a variety of proteins and electrolytes that have protective functions in the oral cavity including lubrication, antimicrobial activity, buffering capacity to neutralize organic acids formed by microorganisms, calcium phosphate homeostasis and enamel remineralization. ${ }^{33}$ Secretion of saliva is coordinated by the autonomic nervous system that includes both parasympathetic and sympathetic nerves. ${ }^{34}$ Water and electrolyte secretion is mainly controlled by the parasympathetic system, acting on muscarinic-cholinergic receptors. Protein synthesis and secretion are regulated by the sympathetic system, acting through $\beta$-adrenergic receptors. Previous studies in streptozotocin-induced diabetic rats have demonstrated morphologic changes in parotid glands such as altered secretory granule substructure, formation of autophagic vacuoles and accumulation of lipid in acini, decreased expression of $\alpha$-amylase and parotid secretory protein as well as impaired response to cholinergic stimulation. ${ }^{35-42}$ In NOD mice, impaired salivary secretion has been associated with lymphocytic infiltration, altered 
Akita -/- 12 wk H\&E stain

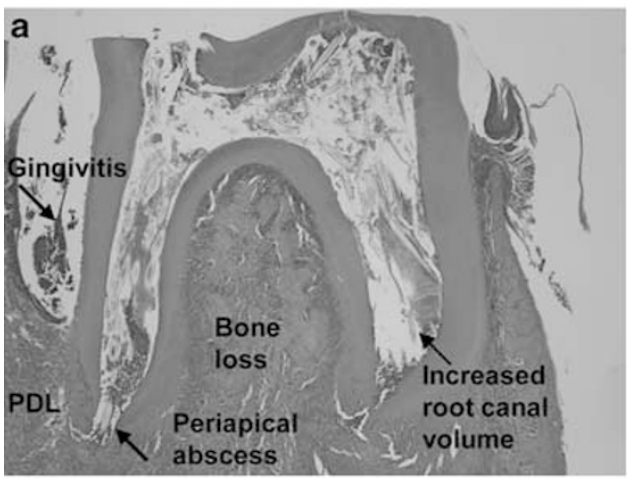

Periapical abscess

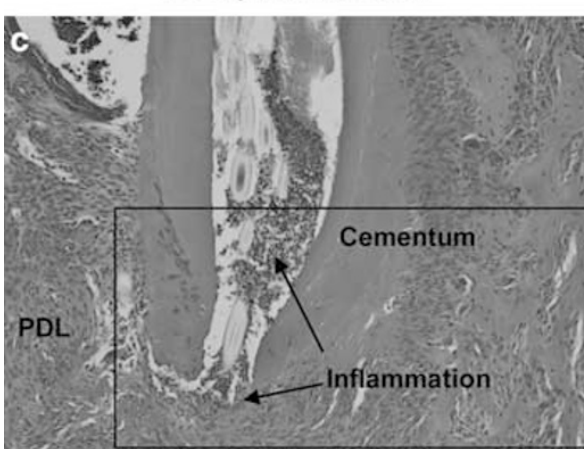

Gram stain

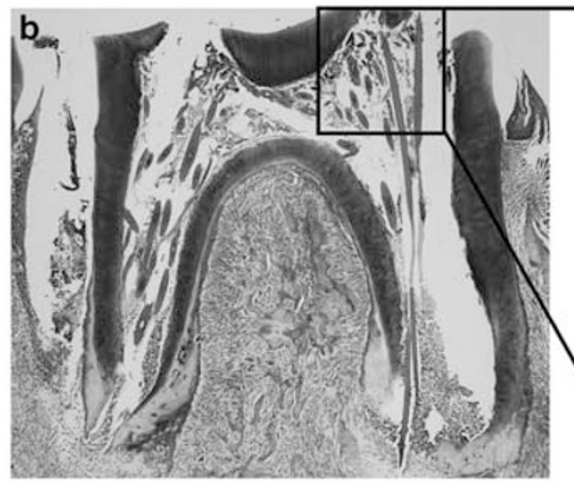

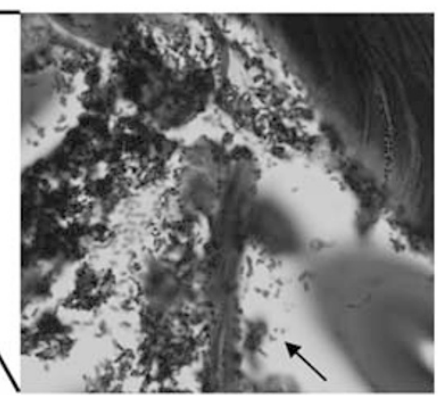

Culture: S. mitis and $P$. pneumotropica
TRAP Stain

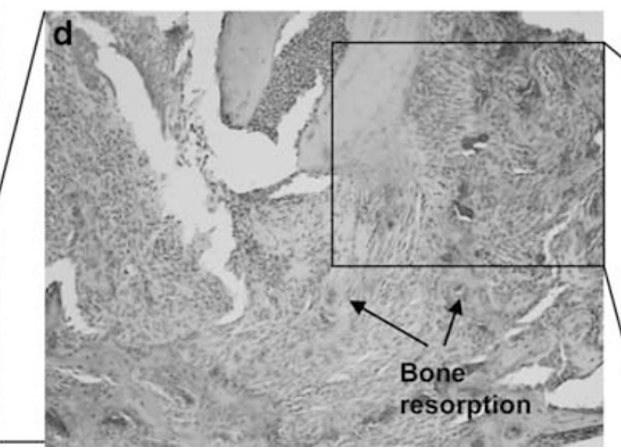

TRAP+ Osteoclasts

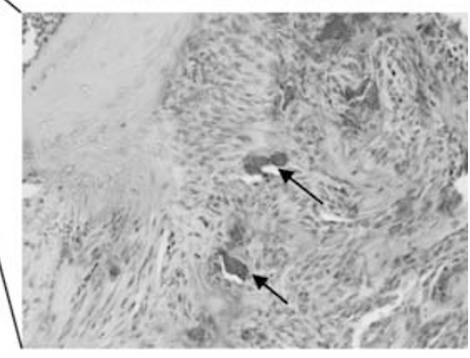

Figure 6 Morphology, bacterial content and osteoclastic bone resorption in first mandibular molars of Akita -/- mice at 12 weeks of age. (a) H\&E stained sections of molar. The crown is destroyed, the pulp chamber is exposed, widened and filled with necrotic/hair shaft debris (arrows). (b) Gram stain of molar. Gram stain showed mixed flora with numerous gram-positive cocci and gram-negative coccobacilli that on culture were identified as $S$. mitus and $P$. pneumotropica, respectively. (c) H\&E stained section of molar root. Periapical abscesses are present with inflammation extending through apical foramen of root into the periodontal ligament (PDL) and alveolar bone (arrows). (d) TRAP stain of molar. Akita $-/-$ mice show numerous TRAP + osteoclasts (red color) in alveolar bone surrounding roots and extensive osteoclast-mediated bone loss around roots (arrows). Original magnification: a: $\times 4$; b: $\times 4, \times 100 ; \mathbf{c :} \times 20 ; \mathbf{d}: \times 20, \times 40$.

$\beta$-adrenergic/muscarinic receptors and/or loss of neurotransmitter responsiveness in salivary glands. ${ }^{43,44}$ Our findings showing decreased saliva production in pilocarpinetreated Akita $-/-$ mice indicate a defect(s) in muscariniccholinergic system in acinar cells. Whether a defect in parasympathetic innervation, decreased responsiveness of muscarinic receptors to stimulation ${ }^{42,43}$ and/or downregulation (reduced numbers) of muscarinic receptors and their signaling pathways ${ }^{44,45}$ similar to that described in NOD mice or streptozotocin-induced diabetic rodents, account for hyposalivation in Akita $-/-$ mice would be of interest.

At the ultrastructural level, parotid glands in Akita -/mice showed increased numbers of secretory granules and alterations in internal granule structure that has been reported in diabetic patients with sialadenosis. ${ }^{35,39,46}$ Granules in WT mice had a bipartite structure with a dense core within a moderately dense background, whereas Akita $-/-$ mice showed granules with poorly defined dense cores and increased numbers of granules with low electron density. As secretory proteins localize within different regions of granules and $\alpha$-amylase expression correlates with dense regions,${ }^{35}$ it is likely that Akita $-/-$ parotid glands have an altered protein profile and reduced amylase. Importantly, previous studies in experimental and human diabetes indicate that insulin treatment may improve salivary gland function and restore saliva constituents. ${ }^{35,39,41}$

Clearly reduced saliva in Akita $-/-$ mice, probably altered in protein, $\mathrm{pH}$ and glucose content, contributed to enamel hypomineralization that may manifest as chalky white teeth. A similar phenotype is also observed in patients with amelogenesis imperfecta because of mutations in the Amel (AmelX) gene or in mice with overexpression of Ambn. ${ }^{47,48}$ During enamel formation, these enamel matrix proteins are essential for growth and maturation of enamel crystals and provide a scaffold for mineral deposition. The effect of hyperglycemia on enamel formation in diabetes has not been well-defined and studies are conflicting. Work by Sasaki et $a l^{49}$ indicated that diabetes in rats did not alter the secretion of Amel by ameloblasts, whereas studies by Karim $^{32,50}$ suggested that diabetes diminished secretion of enamel matrix proteins and led to aberrant deposition. Our findings in 6-week Akita -/- mice support an inhibitory 

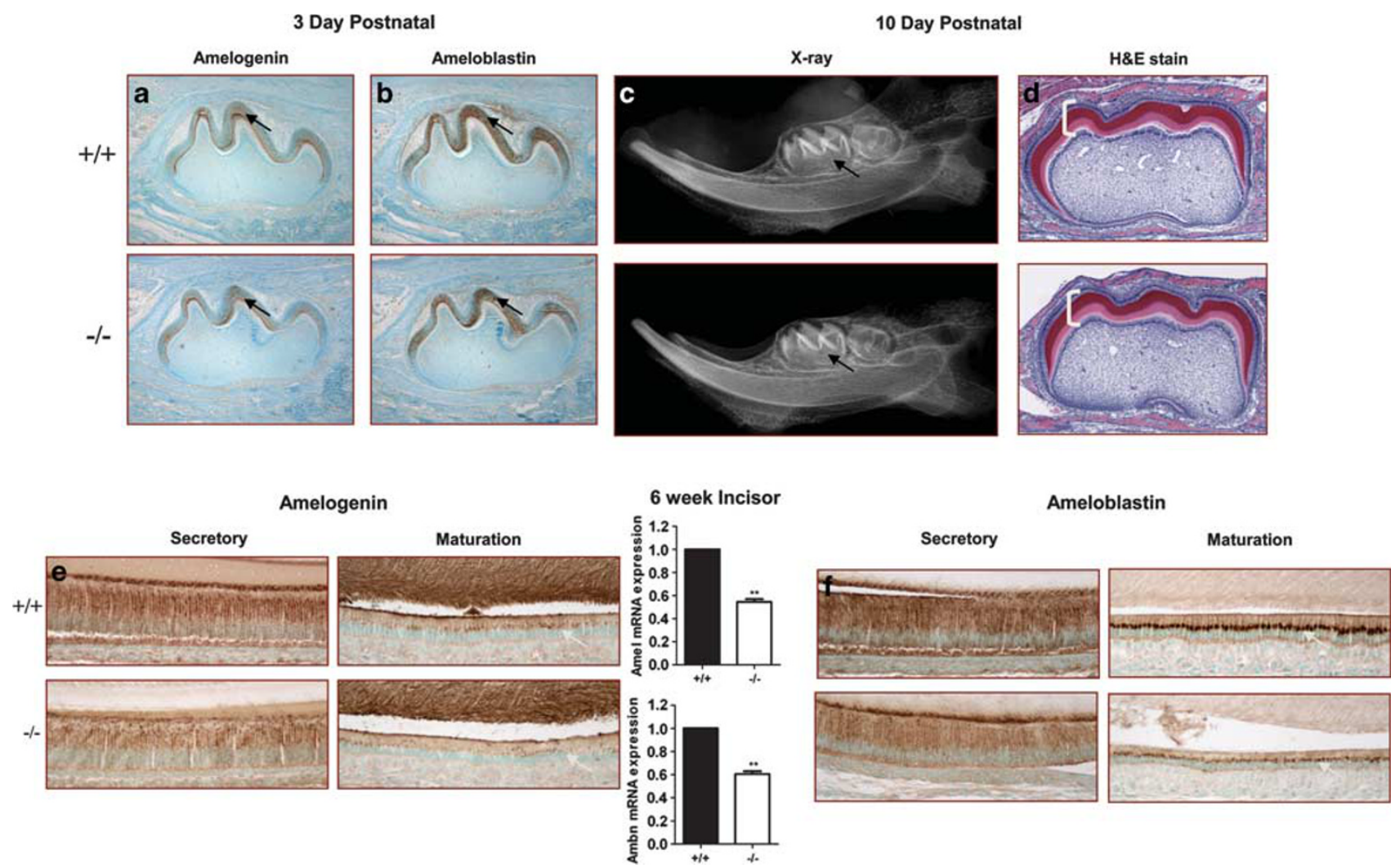

Figure 7 Amelogenin (Amel) and ameloblastin (Ambn) expression in teeth of WT $(+/+)$ and Akita $-/-$ mice at 3 days and 6 weeks of age. (a, b) Immunostains for Amel and Ambn in 3 day first mandibular molars. Amel and Ambn expression in ameloblasts of Akita $-/-$ molars is similar to WT (arrows). (c, d) X-rays and H\&E stains of teeth in WT $(+/+)$ and Akita $-/-$ mice at 10 days of age. Radiographs of Akita $-/-$ mandibles show normal molars and incisors (arrows); histology of Akita $-/-$ molar shows enamel and dentin of normal thickness (bracket). (e, f) Amel and Ambn immunostains of incisors from 6-week-old mice. Akita -/- incisors show decreased Amel and Ambn expression in secretory through maturation stage ameloblasts. Total RNA was isolated from incisors and analyzed by RT-PCR. Bar graphs (center panels) show a reduction of Amel (Amel) and Ambn (Ambn) mRNA levels in Akita $-/$ - compared with WT mice. Mean \pm s.e. ( $n=3$ mice for each genotype) ${ }^{* *} p<0.05$ WT vs Akita $-/-$ mice. Original magnification: a: $\times 10 ; \mathbf{b}: \times 10 ; \mathbf{d}: \times 10$; e: $\times 20 ; \mathbf{f}: \times 20$.

effect of diabetes on enamel matrix proteins and provide the first evidence that hyperglycemia is a potent inhibitor of Amel/Ambn expression that, in turn, likely contributed to chalky white teeth. Altered enamel matrix proteins may further compromise the mineralization process, leading to porous enamel. ${ }^{51}$

Studies indicate that oral bacteria penetrate dentinal tubules through hypomineralized, porous enamel or at sites where dentin is exposed following enamel wearing. ${ }^{26,27}$ Bacterial invasion of dentin leads to pulpal inflammation that is accompanied by formation of reparative dentin. Streptococci are the most common bacteria to invade dentin, probably due to their ability to recognize components in dentinal tubules such as collagen type I that stimulates bacterial adhesion and intra-tubular growth. ${ }^{26}$ In humans, cariogenic microflora present on the surface of fissure, smooth-surface coronal, or root-surface caries consists mainly of mutans streptococci, lactobacilli and Actinomyces spp. ${ }^{52}$ In type 1 diabetic patients, studies point to a positive correlation between acidogenic microorganisms such as lactobacilli and risk of caries development. ${ }^{7}$ Our findings in Akita $-/-$ mice indicate progressive dentinal tubule invasion and acute pulpitis from 6 to 9 weeks, because of infection with S. mitis. Interestingly, S. mitis, albeit not a cariogenic bacteria, is an acid-producing organism and it is tempting to speculate that reduced saliva, along with increased glucose and low $\mathrm{pH}$ levels in saliva, conditions known to promote the growth of acidogenic organisms, ${ }^{52}$ favored $S$. mitis infection in Akita $-/-$ molars and exacerbated enamel/dentin demineralization and pulp destruction.

Dental pulp cells have the ability to resist and repair injuries. This process involves pulp cell migration to the site of injury, proliferation, extracellular matrix remodeling and differentiation into odontoblasts that are required for secondary and tertiary dentin formation. ${ }^{53}$ Previous studies indicate that hyperglycemia adversely affects pulpal healing. In STZ-induced diabetic rats with exposed pulps capped with mineral trioxide, hyperglycemia was associated with decreased pulp and dentin repair and increased inflammation. ${ }^{54}$ Under high glucose conditions in vitro, osteoblasts 

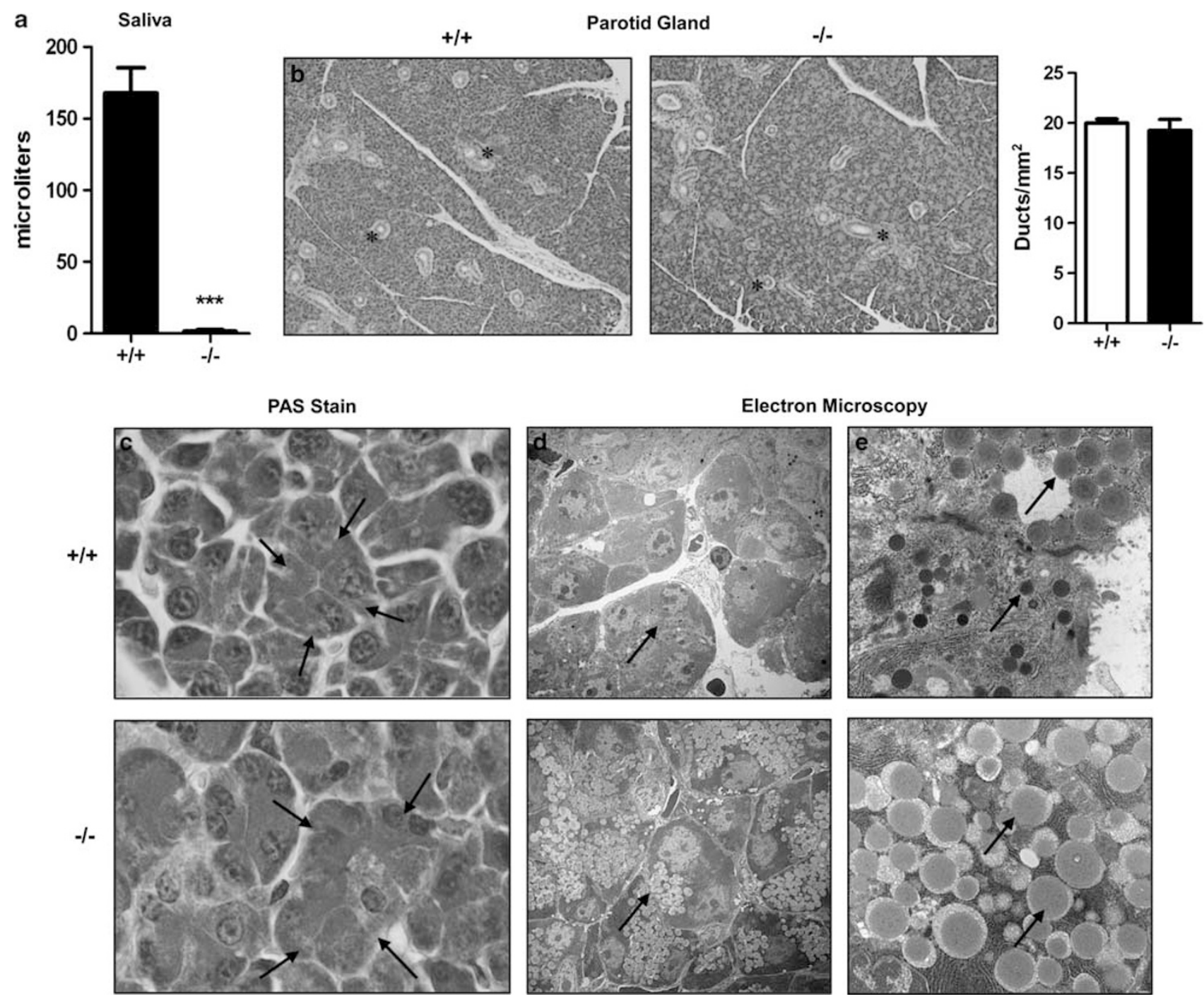

Figure 8 Saliva production and parotid gland morphology in WT $(+/+)$ and Akita $-/$ - mice at 6 weeks of age. (a) Quantification of saliva after pilocarpine injection. Mice were injected with pilocarpine as described in Materials and Methods section. WT mice showed abundant saliva production, whereas Akita $-/-$ mice produced little or no saliva (bar graph). Mean \pm s.e. $\left(n=3-4\right.$ mice for each genotype) ${ }^{* *} p<0.001$ WT vs Akita $-/-$ mice. (b, c) H\&E stains of parotid glands harvested from the same mice in (a). Parotid glands in Akita $-/$ - mice show normal architecture and no inflammation. Bar graph shows that the number of ducts (asterisks) per $\mathrm{mm}^{2}$ of parotid tissue in Akita $-/-$ mice was similar to that in WT mice. Mean \pm s.e. ( $n=4$ mice for each genotype) ${ }^{*} P>0.05$ WT vs Akita $-/$ - mice. (c) PAS stain of parotid gland. Akita $-/$ - parotid acini show increased PAS + secretory granules (arrows). (d, e) Transmission electron microscopy (TEM) of parotid glands. Parotid gland acini in Akita -/- mice show increased secretory granules compared with WT (arrows). WT acini show dark granules with dense cores, whereas Akita -/- acini show granules with low electron density (arrows). Original magnification: b: $\times 10$; $\mathbf{c} \times 40$; d: $\times 2500$; e: $\times 15000$.

and periodontal ligament cells show decreased proliferation and differentiation. ${ }^{55,56}$ In cultured MD10-F2 pulp cells, we observed that high D-glucose, inhibited proliferation and dramatically decreased mineralized nodule formation compared with L-glucose controls. These results suggest that high glucose, via a metabolic effect, acts as an inhibitor of pulp cell proliferation, differentiation and reparative processes within the pulp chamber.

Failure of pulp cell repair in Akita -/ - mice from 6 to 12 weeks was evident because tertiary dentin formation could not keep pace with dentinal injury from severe wearing and acute pulpitis rapidly spread from the crown and led to severe periodontitis. In addition to glucose, advanced glycation end products (AGEs) may contribute to periodontal destruction seen in diabetic humans and rodents. ${ }^{4}$ Accumulation of AGEs in gingival tissues of diabetics is associated with the development of periodontitis. This effect is likely due to the ability of AGEs to inhibit cell proliferation, downregulate collagen expression, induce collagen crosslinking and inflammatory responses that, in turn, impair wound healing. ${ }^{57-59}$ Thus, in Akita -/- mice, hyperglycemia likely leads to accumulation of AGEs in pulp and periodontal 


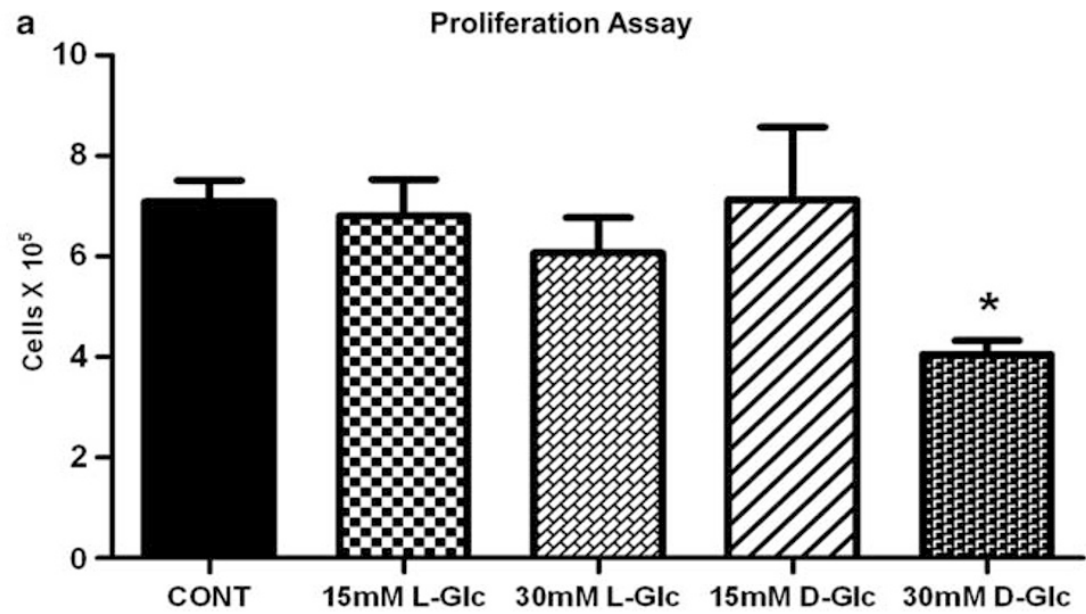

b

Differentiation Assay - Von Kossa Stain
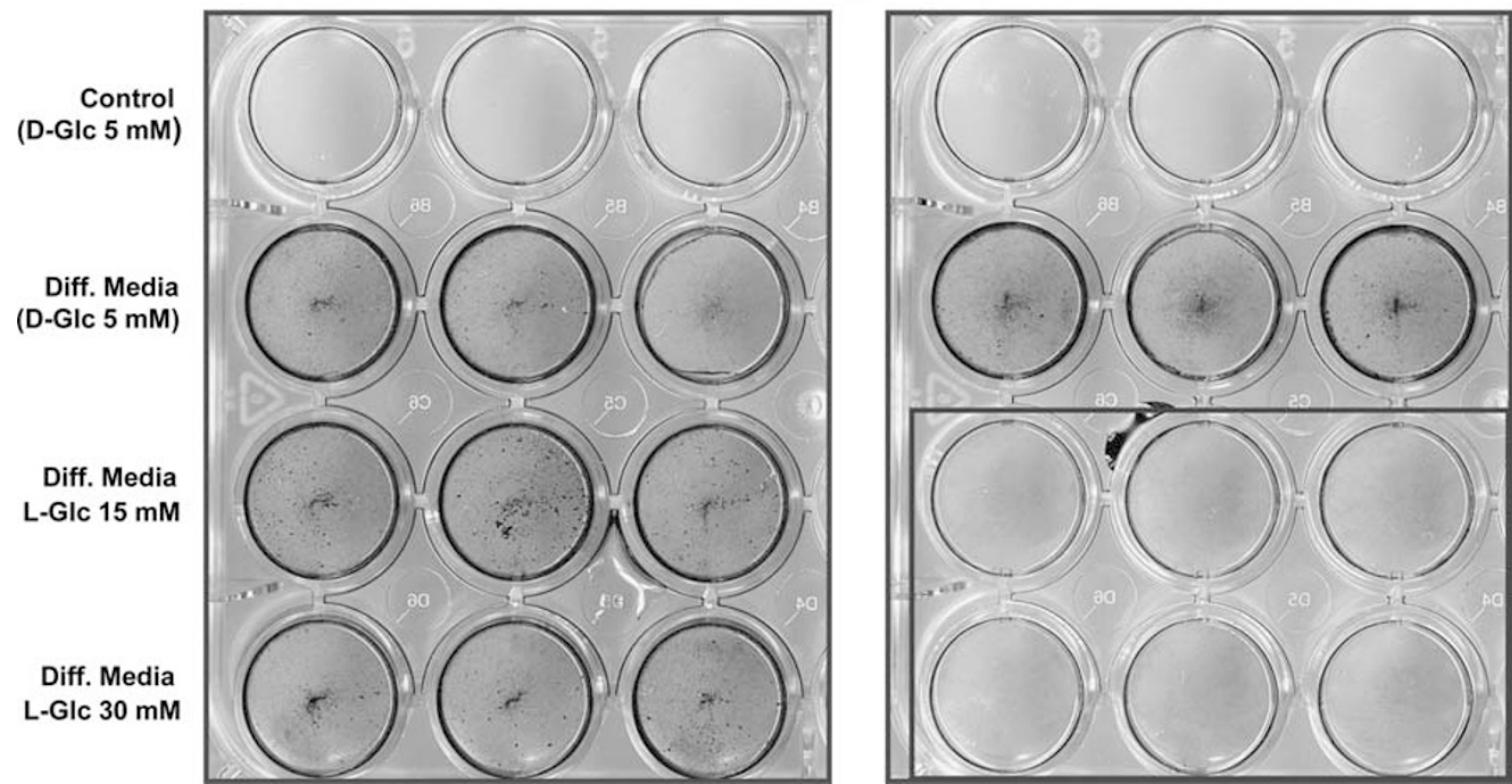

Control

(D-Glc $5 \mathrm{mM}$ )

Diff. Media

(D-Glc $5 \mathrm{mM}$ )

Diff. Media

D-GIc $15 \mathrm{mM}$

Figure 9 Effect of high glucose (glc) on MD10-F2 pulp cell proliferation and differentiation. (a) Proliferation assay. Cells were plated in complete $\alpha$-MEM that contains $5.5 \mathrm{mM}$ D-glucose (normal glucose control). After $24 \mathrm{~h}$, cells were placed in $\alpha$-MEM with $2 \%$ FCS and incubated in the presence and absence of high D-glucose (15 or $30 \mathrm{mM})$. L-glucose $(15$ or $30 \mathrm{mM})$ was used as an osmotic control. Cell numbers were counted on day 4 . Bar graph shows that high D-glucose $(30 \mathrm{mM})$ inhibited pulp cell proliferation compared with $5 \mathrm{mM}$ D-glucose (cont) and L-glucose-treated controls. Data represents three separate experiments, each performed in triplicate wells. Mean \pm s.e., ${ }^{*} P<0.05$, D-glc $(30 \mathrm{mM})$ vs Cont and L-glc controls. (b) Differentiation assay. Cultures were incubated in differentiation medium containing $5 \mathrm{mM}$ D-glucose or in differentiation medium with high D-glucose or high D-glucose (15 or $30 \mathrm{mM}$ ). As a control, cultures were incubated without differentiation medium. Medium was changed every 2 days and, on day 12, cultures were stained with von Kossa. Control wells lack nodule formation, whereas cultures incubated in differentiation medium containing either $5 \mathrm{mM}$ D-glucose or L-glucose show mineralized nodules (black color). Compared with L-glucose controls, D-glucose dramatically inhibited mineralized nodule formation. Representative of three separate experiments, each performed in triplicate wells.

structures and compounds the detrimental effects of hyperglycemia on dental tissues.

In summary, our data support a strong link between the degree of glycemic control and loss of salivary gland function in type 1 diabetes. Moreover, hyperglycemia and reduced saliva production are key determinants of enamel attrition and invasion by oral bacteria. Early detection of hyperglycemia and hyposalivation in diabetic patients is essential for preserving enamel integrity and preventing the onset of acute pulpitis. The Akita $-1-$ mouse provides a unique translational model for evaluating clinical approaches to prevent the spectrum of oral diseases encountered in diabetics. Further elucidation of glucosemediated effects on dental and salivary gland cells may suggest novel therapeutic strategies to ameliorate tooth decay/periodontal injury in a growing population of children with type 1 diabetes and promote oral health throughout adulthood. 


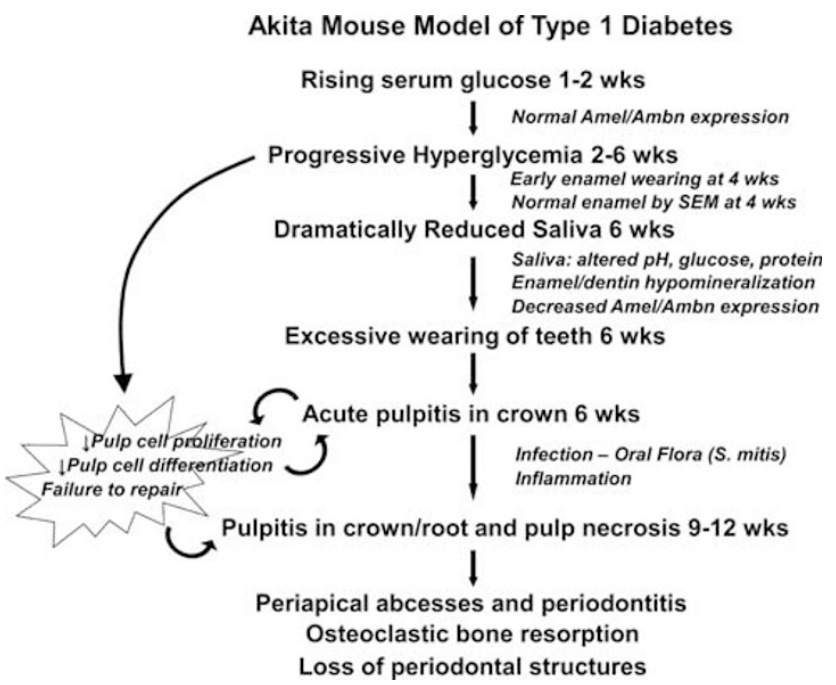

Figure 10 Diagram of Akita mouse model of type 1 diabetes. Summary provided in first paragraph of the Discussion section.

\section{ACKNOWLEDGEMENTS}

We thank the micro-CT Core Facility at UTHSCSA for their assistance in analyzing dental tissues and Drs Alan Lin and Yi Zhou (Comprehensive Dentistry, UTHSCSA) for assisting with saliva/salivary gland collection. We also thank Chris Edwards and the Microscopy and Image-analysis Laboratory at the University of Michigan School of Medicine for scanning electron microscopic studies. This work has been supported, in part, by funding from the National Institutes of Health, NIDCR (DE015857, SAW) and (DE0211084, C-KY).

\section{DISCLOSURE/CONFLICT OF INTEREST}

The authors declare no conflict of interest.

1. National Institute of Diabetes and Digestive and Kidney Diseases. National Diabetes Statistics 2007;http://diabetes.niddk.nih.gov/dm/ pubs/statistics.

2. Lamster IB, Lalla E, Borgnakke WS, et al. The relationship between oral health and diabetes mellitus. J Am Dent Assoc 2008;139:19S-24S.

3. Ryan ME, Carnu O, Kamer A. The influence of diabetes on the periodontal tissues. J Am Dent Assoc 2003;134:34S-40S.

4. Sreebny LM, Yu A, Green A, et al. Xerostomia in diabetes mellitus. Diabetes Care 1992;15:900-904.

5. Moore PA, Guggenheimer J, Etzel KR, et al. Type 1 diabetes mellitus, xerostomia, and salivary flow rates. Oral Surg Oral Med Oral Pathol Oral Radiol Endod 2001;92:281-291.

6. Miko S, Smbrus SJ, Sahafian S, et al. Dental caries and adolescents with type 1 diabetes. Br Dent J 2010;208:1-4.

7. Twetman $\mathrm{S}$, Hohnsson I, Birkhed $\mathrm{D}$, et al. Caries incidence in young type 1 diabetes mellitus patients in relation to metabolic control and caries-associated risk factors. Caries Res 2002;36:31-35.

8. Siudikiene J, Machiulskiene V, Nyvad B, et al. Dental caries increments and related factors in children with type 1 diabetes mellitus. Caries Res 2008:42:354-362.

9. Wang J, Takeuchi T, Tanaka S, et al. A mutation in the insulin 2 gene induces diabetes with severe pancreatic beta-cell dysfunction in the Mody mouse. J Clin Invest 1999;103:27-37.

10. Gyurko R, Siqueira CC, Caldon N, et al. Chronic hyperglycemia predisposes to exaggerated inflammatory response and leukocyte dysfunction in Akita mice. J Immunol 2006;177:7250-7256.

11. Atar M, Yasmin R, Sharma R, et al. Of mice and mutations: phenotypic effects of the diabetic $\mathrm{db} / \mathrm{db}$ and ob/ob mutations on the skull and teeth of mice. Eur Arch Paediatric Dentistry 2008;9:37-40.

12. Atar $M$, Davis GR, Verry $P$, et al. Enamel mineral concentration in diabetic rodents. Eur Arch Paediatric Dentistry 2007;8:195-200.
13. Atar $M$, Atar-Zwillenberg $D R$, Verry $P$, et al. Defective enamel ultrastructure in diabetic rodents. Int J Paediatric Dentistry 2004;14: 301-307.

14. Noren J, Grahnen H, Magnusson BO. Maternal diabetes and changes in the hard tissues of primary teeth. III. A histologic and microradiographic study. Acta Odontol Scand 1978;36:127-135.

15. Silva-Sousa YTC, Peres LC, Foss MC. Enamel hypoplasia in a litter of rats with alloxan-induced diabetes mellitus. Braz Dent J 2003;14:87-93.

16. Adler $P$, Wegner $H$, Bohatka L. Influences of age and duration of diabetes on dental development in children. J Dent Res 1973;52:535-537.

17. Fouad A, Barry J, Russo J, et al. Periapical lesion progression with controlled microbial inoculation in a type 1 diabetic mouse model. J Endod 2002;28:8-16.

18. Yoshioka M, Kayo T, Ikeda $T$, et al. A novel locus, Mody4, distal to D7Mit189 on chromosome 7 determines early-onset NIDDM in nonobese C57BL/6 (Akita) mutant mice. Diabetes 1997:46:887-894.

19. Kayo T, Koizumi A. Mapping of murine diabetogenic gene Mody on chromosome 7 at D7Mit258 and its involvement in pancreatic islet and $\beta$ cell development during the perinatal period. J Clin Invest 1998;101:2112-2118.

20. Simmer JP, Hu Y, Lertlam $R$, et al. Hypomaturation enamel defects in Klk4 knockout/LacZ knockin mice. J Biol Chem 2009:284:19110-19121.

21. Abboud-Werner S, Gluhak-Heinrich J, Woodruff $\mathrm{K}$, et al. Targeted expression of csCSF-1 in op/op mice ameliorates tooth defects. Arch Oral Biol 2007;52:432-443.

22. Wittrant $Y$, Sriniketan Bhandari B, Abboud $H$, et al. PDGF up-regulates CSF-1 gene transcription in ameloblast-like cells. J Dent Res 2008;87: 33-38.

23. Nakamoto T, Srivastava A, Romanenko VG, et al. Functional and molecular characterization of the fluid secretion mechanism in human parotid acinar cells. Am J Physiol Regul Integr Comp Physiol 2007;292: R2380-R2390.

24. Lin $A L$, Johnson $D A, W u ~ Y$, et al. Measuring short-term gammairradiation effects on mouse salivary gland function using a new saliva collection device. Arch Oral Biol 2001;46:1085-1089.

25. Chen S, Rani $S, W u ~ Y$, et al. Differential regulation of dentin sialophosphoprotein expression by Runx2 during odontoblast cytodifferentiation. J Biol Chem 2005;280:29717-29727.

26. Fagrell TG, Lingstrom $P$, Olsson $S$, et al. Bacterial invasion of dentinal tubules beneath apparently intact but hypomineralized enamel in molar teeth with molar incisor hypomineralization. Int J Paediatr Dent 2008;18:333-340.

27. Love RM, Jenkinson HF. Invasion of dentinal tubules by oral bacteria. Crit Rev Oral Biol Med 2002;13:171-183.

28. Aas JA, Paster BJ, Stokes LN, et al. Defining the normal bacterial flora of the oral cavity. J Clin Microbiol 2005;43:5721-5732.

29. Scharmann W, Heller A. Survival and transmissibility of Pasteurella pneumotropica. Lab Anim 2001;35:163-166.

30. lughetti L, Marino R, Bertolani MF, et al. Oral health in children and adolescents with IDDM: a review. J Pediatr Endocrinol Metab 1999;12:603-610.

31. Miralles L, Silvestre FJ, Hernandez-Mijares A, et al. Dental caries in type 1 diabetics: influence of systemic factors of the disease upon the development of dental caries. Med Oral Pathol Oral Cir Bucal 2006;11: E256-E260.

32. Karim AC. An ultrastructural study of the effect of streptozotocin on the secretory ameloblasts of the rat incisor. Anat Anz 1983;153: 119-136.

33. Hara AT, Zero DT. The caries environment: saliva, pellicle, diet, and hard tissue ultrastructure. Dent Clin N Am 2010;54:455-467.

34. Garrett JR. Historical introduction to salivary secretion. In: Garrett JR Ekstrom J, Anderson LC (eds). Glandular Mechanisms of Salivary Secretion, Volume 10. Karger: Basel, 1998; 1-20.

35. Piras M, Hand AR, Mednieks Ml, et al. Amylase and cyclic amp receptor protein expression in human diabetic parotid glands. J Oral Pathol Med 2010;39:715-721.

36. Hand AR, Weiss RE. Effects of streptozotocin-induced diabetes on the rat parotid gland. Lab Invest 1984;51:429-440.

37. Anderson LD, Garret JR. Lipid accumulation in the major salivary glands of streptozotocin-diabetic rats. Arch Oral Biol 1986;31:469-475.

38. Szczepanski A, Mednieks MI, Hand AR. Expression and distribution of parotid secretory proteins in experimental diabetes. Eur J Morphol 1998;36(Suppl):240-246. 
39. Mednieks MI, Szczepanski A, Clark B, et al. Protein expression in salivary glands of rats with streptozotocin diabetes. Int J Exp Patholo 2009:90:412-422.

40. Cutler LS, Pinney HE, Christian C, et al. Ultrastructural studies of rat submandibular gland in streptozotocin induced diabetes mellitus. Virchows Arch A Patholo Anat Histol 1979;382:301-311.

41. Anderson LC. Effects of alloxan diabetes on rat parotid gland and saliva. Am J Physiol 1983;245:G431-G437.

42. Watanabe M, Yamagishi-Wang H, Kawaguchi M. Lowered susceptibility of muscarinic receptor involved in salivary secretion of stretozotocininduced diabetic rats. Jpn J Pharmacol 2001;87:117-124.

43. Yamamoto $H$, Ishibashi $K$, Nakagawa $Y$, et al. Detection of alterations in the levels of neuropeptides and salivary gland responses in the nonobese diabetic mouse model for autoimmune sialoadenitis. Scand J Immunol 1997;45:55-61.

44. Yamamoto $\mathrm{H}$, Sims $\mathrm{NE}$, Macauley $\mathrm{SP}$, et al. Alterations in the secretory response of non-obese diabetic (NOD) mice to muscarinic receptor stimulation. Clin Immunol Immunopathol 1996;78:245-255.

45. Fedirko NV, Kruglikov IA, Kopach OV, et al. Changes in functioning of rat submandibular salivary gland under streptozotocin-induced diabetes are associated with alterations of $\mathrm{Ca}^{2+}$ signaling and $\mathrm{Ca}^{2+}$ transporting pumps. Biochemica et Biophysica Acta 2006;1762:294-303.

46. Mandel L, Patel S. Sialadenosis associated with diabetes mellitus: case report. J Oral Maxillofac Surg 2002;60:696-698.

47. Wright JT, Torain M, Long K, et al. Amelogenesis imperfect: genotypephenotype studies in 71 families. Cells Tissues Organs 2011;194:279-283.

48. Paine $\mathrm{ML}$, Wang $\mathrm{HJ}$, Luo $\mathrm{W}$, et al. A transgenic animal model resembling amelogenesis imperfect related to ameloblastin overexpression. J Biol Chem 2003;278:19447-19452.
49. Sasaki T, Ramamurthy NS, Golub LM. Insulin-deficient diabetes impairs osteoblast and periodontal ligament fibroblast metabolism but does not affect ameloblasts and odontoblasts: response to tetracycline(s) administration. J Biol Buccale 1990;18:215-226.

50. Karim AC. An ultrastructural study of the effect of a diabetogenic dose of alloxan on the secretory ameloblasts of the rat incisor. Am J Anat 1983;166:83-98.

51. Rodd HD, Boissonade FM, Day PF, et al. Pulpal status of hypomineralized permanent molars. Pediatr Dent 2007;29:514-520.

52. Marsh PD. Microbiology of dental plaque biofilms and their role in oral health and caries. Dent Clin N Am 2010;54:441-454.

53. Farges JC, Romeas A, Melin M, et al. TGF-beta 1 induces accumulation of dendritic cells in the odontoblastic layer. J Dent Res 2003;82: 652-656.

54. Garber SE, Shabahang S, Escher AP, et al. The effect of hyperglycemia on pulpal healing in rats. J Endod 2009;35:60-62.

55. Kim HS, Park JW, Yeo SI, et al. Effects of high glucose on cellular activity of periodontal ligament cells in vitro. Diabetes Res Clin Pract 2006;74: 41-47.

56. Balint E, Szabo P, Marshall CF, et al. Glucose-induced inhibition of in vitro bone mineralization. Bone 2001;28:21-28.

57. Ren $\mathrm{L}, \mathrm{Fu} Y$, Deng $\mathrm{Y}$, et al. Advanced glycation end products inhibit the expression of collagens type I and III by human gingival fibroblasts. J Periodontol 2009;80:1166-1173.

58. Valikangas L, Pekkala E, Larmas $M$, et al. The effects of high levels of glucose and insulin on type I collagen synthesis in mature human odontoblasts and pulp tissue in vitro. Adv Dent Res 2001;15:72-75.

59. Catanzaro O, Dziubecki D, Lauria LC, et al. Diabetes and its effects on dental pulp. J Oral Sci 2006;48:195-199. 